\title{
A Review of the Conceptualization and Operational Manage- ment of Seaport Microgrids on the Shore and Seaside
}

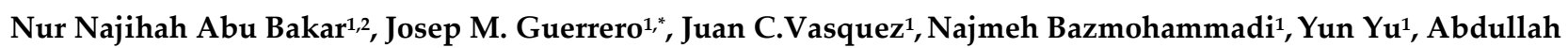 \\ Abusorrah $^{3}$ and Yusuf A. Al-Turki ${ }^{3}$
}

1 Center for Research on Microgrids (CROM), AAU Energy, Aalborg University, 9220 Aalborg East, Denmark; nurnbab@energy.aau.dk; joz@energy.aau.dk; @juqenergy.aau.dk; naj@energy.aau.dk; yyu@energy.aau.dk

2 Faculty of Electrical Engineering Technology, University Malaysia Perlis (UniMAP), Kampus Pauh Putra, 02600 Arau, Perlis, Malaysia; nurnajihah@unimap.edu.my

3 Center of Research Excellence in Renewable Energy and Power Systems, Department of Electrical and Computer Engineering, Faculty of Engineering, K. A. CARE Energy Research and Innovation Center, King Abdulaziz University, Jeddah 21589, Saudi Arabia

* Correspondence: joz@energy.aau.dk

\begin{abstract}
Seaports are well known as the medium that has evolved into the central link between sea and land for complex marine activities. The growth in maritime logistics especially necessitates a large volume of energy supply to maintain the operation of sea trade, resulting in an imbalance between the generation and demand sides. Future projections for three major concerns show an increase in load demand, cost of operation, and environmental issues. In order to overcome these problems, integrating microgrids as an innovative technology in the seaport power system appears to be a vital strategy. It is believed that microgrids enhance the seaport operation by providing sustainable, environmentally friendly, and cost-effective energy. Despite the fact that microgrids are well established and widely used in a variety of operations on land, their incorporation into the seaport is still limited. The involvement of a variety of heavy loads such as all-electric ships, cranes, cold ironing, and buildings infrastructure makes it a complicated arrangement task in several aspects, which necessitate further research and leave space for improvement. In this paper, an overview of the seaport microgrids in terms of their concepts, requirements, and operation management is presented. It provides the perspectives of integrating the microgrid concept into a seaport from both shore side and seaside as a smart initiative for the green ports vision. Future research directions are discussed towards the development of more efficient marine power system.
\end{abstract}

Keywords: cold ironing; electrification; operation management; renewable energy source; seaport microgrids; shipboard microgrid; maritime

\section{Introduction}

Recent decades have witnessed the rapid expansion of the global economy. This development was motivated by an even faster escalation in international trade. Seaport plays a significant role in this economic liberalization as sea trading is in high demand due to its cheap prices and capability to support good transportation in a large volume through cargo services. Currently, the marine transport network accounts for more than 90 percent of global trade, and according to the International Maritime Organization (IMO) annual report, it is predicted to be tripled by 2050 [1][2]. Seaports have become complex hubs due to the multifunctional operations that need to comply with various factors such as marine regulations, technologies, transportation, operational, and policy requirements. Hence, high investment is required to expand ports facilities, infrastructure as well as enhancing their operation management and maintenance to boost up all the marine operations. 
The increasing number of ships, cranes, and trucks for port transportation requires high-energy consumption. Besides, the size of ships is also much bigger nowadays with hundreds of meters long and kiloton weights. The world's largest cruise in 2020 was Symphony of the Seas with 228081 gross tonnages, 361 meters in length, 65.7 meters in width, and a designed capacity of up to 6680 passengers [3]. All of these factors consequently lead to the huge volume of fossil fuel burning to fulfill the whole load at the port.

Overuse of energy always leads to the unbalance between generation and distribution, which makes the energy system inefficient and prone to frequent power outages. The Kenya Ports Authority (KPA) reported economic losses of over $\$ 800,000$ after a 3-day blackout in 2013, which resulted in the motionless cranes for over 75 hours while no cargo was loaded or off-loaded from the container vessels [4]. In this situation, usually, ports rely on diesel-powered generators as a backup for emergency usages during temporary power disruption. However, it does not comply with ports' environmental requirements.

Research in developing more efficient power systems for port operations has attracted special interest in recent years. Incorporating renewable energy sources (RESs) and energy storage system (ESS) technologies through microgrid systems has been viewed as an essential route. By utilizing microgrids, power generation is not limited to the conventional fossil-based resources anymore, and the flexibility to integrate multiple RESs like wind turbines (WTs), photovoltaic (PV) systems, biomass, ocean energy, hydrogen, and geothermal which all contribute to sustainable energy is introduced in an efficient way. Deploying ESS at seaport will enhance better energy distribution by providing backup energy during emergencies and giving the capability of storing excess energy generation to the ports.

The promising benefits of microgrids to the marine sector can be categorized into four groups, namely energy efficiency, economic, environmental, and security benefits. However, the variation of heavy loads energy demand at the port both at the shore and seaside results in a complex control for seaport microgrids. Although microgrids coordination is an undeniably established technology in land-based applications that currently provides tremendous economic and environmental benefits, there are still several issues that need to be addressed before incorporating them into maritime applications. Besides, the literature in this field is far from conclusive. Many aspects need further exploration to ensure the optimal benefits of integrating the microgrid concept into seaports.

In this perspective, this paper presents an overview of the seaport microgrids concept and its operational measures for seaport applications on both shore and seaside (shipboard microgrid). Besides, from a macro perspective to the most co-occurrence researches, VOSviewer visualization analysis is provided to illustrate the trending and probable future research of microgrids application into maritime sector.

The rest of this paper is organized as follows. Section 2 is dedicated to introducing the variation of load demand and current major issues at ports as well as energy evolution in seaports over time. In Section 3, the conceptualization of microgrids on shore and seaside is presented, while topology and operation management of the seaport microgrids are also discussed. In addition, a few constraints and potential aspects for further research investigation are highlighted in Section 4. Finally, the significant findings of the paper are summarized in Section 5.

\section{Seaport}

Seaports are well known as significant interfaces for both sea and land transportations. This activity is supported by geographically constructed space, as shown in Figure 1 , where it is located at a crossroads between the sea and land. Port is one of the large parts of the industrial sector for economic and social development over the world. Demand for logistics globally arising the density of sea traffic. 


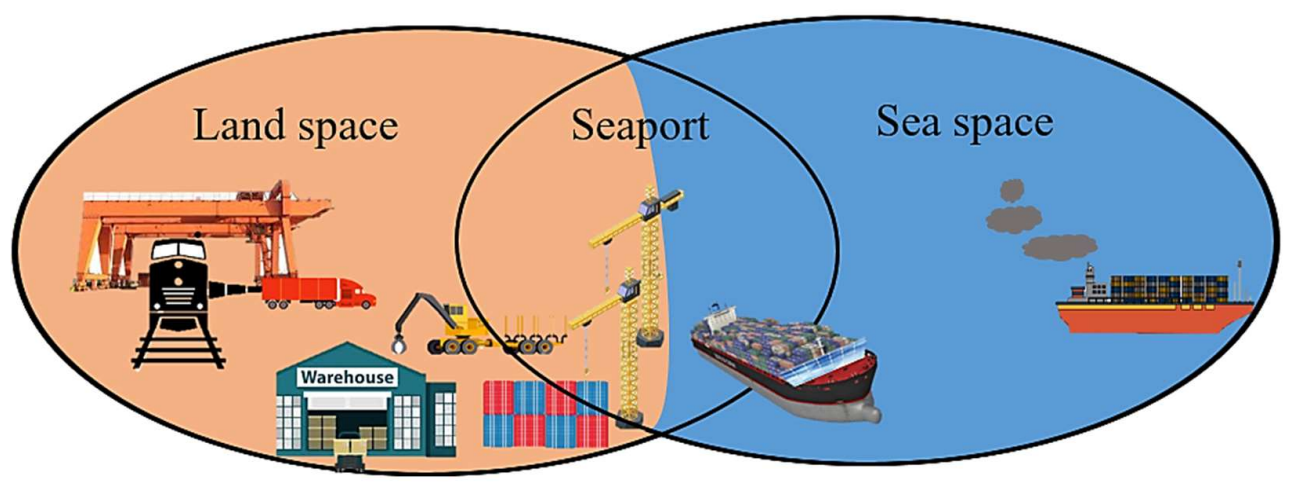

Figure 1. Seaport intersection between land and sea space [5].

Seaport is influenced by the socio-economic fluctuations characterized by the need for country development through trading activities, by globalization contexts, constraints, technology, environmental, and type of maritime transportation used. It has become multifaceted centers defined by multifunctional operations and load handle at the seaport such as logistics and commercial activities, freight services, information center, shipping, merchandising, and exports. It aggressively changes along with global development to compare with the conventional port as shown in Figure 2, where the first generation of ports in the early 1960s only focused on the modes of transportation without any trading and commercial activities. It then experienced more advances in terms of technology, networking, international trading, and logistics. In the $5^{\text {th }}$ generation, ports are moving toward smart ports employing automation, advanced technologies, hybrid, intelligent infrastructure, and efficient energy management systems. This evolution of course causing to the changes in the port definition over time following the seaport concept and functions that are fulfilled in the port.

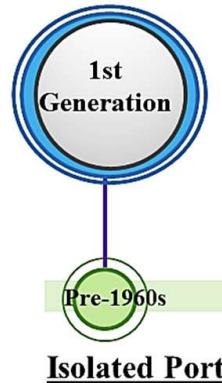

Interface between two modes(land and sea) of transport only
Expended Port Transport, industrial \& commercial activities

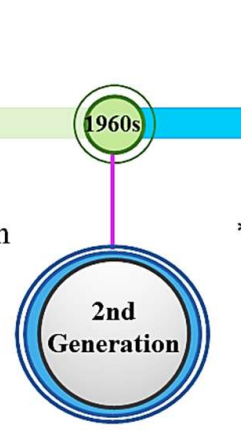

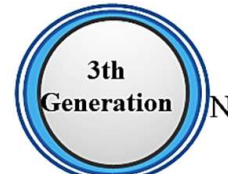

Integrated Port etworking oriented with wordwide alliances of containership owner

\section{Container Port}

*Transportation centre integrated

*logistic platform for international trading
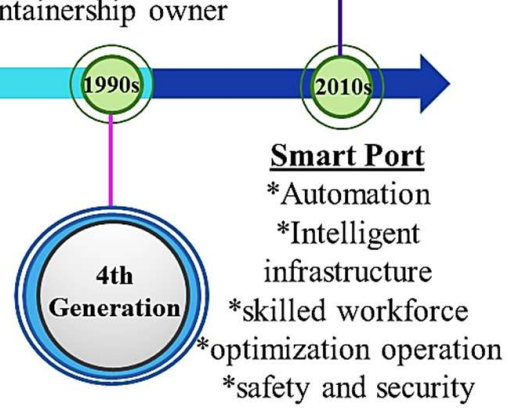

Figure 2. The evolution of the seaport functions over time [5][6][7][8].

\subsection{Port activities and power consumers}

The port engagement with regard to energy can be classified into energy generation and power consumption mainly in the form of electricity and fuel. It is crucial to comprehend the load components and monitor energy-related activities taking place within the port before initiate any energy planning. The purpose is to analyze the amount of energy demand and ensure that there is enough power supply to prevent power shortages. However, load profile measures at seaport vary according to several factors such as the type of port and activities conducted at that particular port. 
Seaports by definition can be viewed as centers of economic activities associated with any kind of arrival (tourist or goods), service of ships, and cargoes [9]. The most common ports can be categorized into commercial/industrial ports, container terminal ports, and intermodal ports [10]. An industrial port is where socio-economic and trading activities are actively running [5]. Harbors and ships are the fundamental drivers of international trade. Meanwhile, a container terminal is a facility where cargo containers are transferred for onward destination [11]. As for the intermodal port, it is referred to the use of two or more modes of transportation to move a unit of freight between its origin and destination in a systematic fashion [12]. It provides road facilities, railway terminals, and warehouses to facilitate the handling of goods and storage services. Meanwhile, Nikolaos Sifakis and Theocharis Tsoutsos [13] group ports into three typologies which are local ports, national ports, and international ports. All these categories are classified based on their characteristic, region of the port, the volume of loads it serves, vessel type, port's operational and service, annual number of passengers, and the annual number of ships berth in and out from the port. Table 1 summarizes the port categories based on these typologies.

Table 1. Port typology based on its characteristic [13].

\begin{tabular}{|c|l|}
\hline Port typology & \multicolumn{1}{|c|}{ Characteristics } \\
\hline \multirow{3}{*}{ Local port } & Serves for local needs \\
& Limited space and capacity \\
& Small size \\
& No logistic activity handling \\
& Do not support cruise ships \\
& Boats, vessels, yachts, and small-sized ships $<500$ passen- \\
& gers \\
\hline National port & Serves country needs \\
& Medium-sized (larger than local port) \\
& Cover all ships type with small logistic and cruise \\
& activities \\
& Medium-sized ships $<2500$ passengers, cargo (packages), \\
& and logistics (only trucks) \\
\hline \multirow{5}{*}{ International port } & Serves international needs \\
& Largest sized \\
& Provide huge logistic infrastructure \\
& Cruise ships $>2500$ passengers, cargo, containerships, \\
& RTG cranes \\
\hline
\end{tabular}

Geographically, a seaport is a point of interaction between the two domains, which are land space and sea involving two modes of transportation (water and road traffic) with different characteristics. The transition between sea and shore side is referred to as the intermediate region. From this perspective, the area in the seaport can be sorted into seaside, shore side, and intermediate space. Each space is utilized for a different type of activity, transportation, and application, all of which have an impact on the amount of energy demand. Figure 3 illustrates the most common activities running in the seaport area and its load components. 


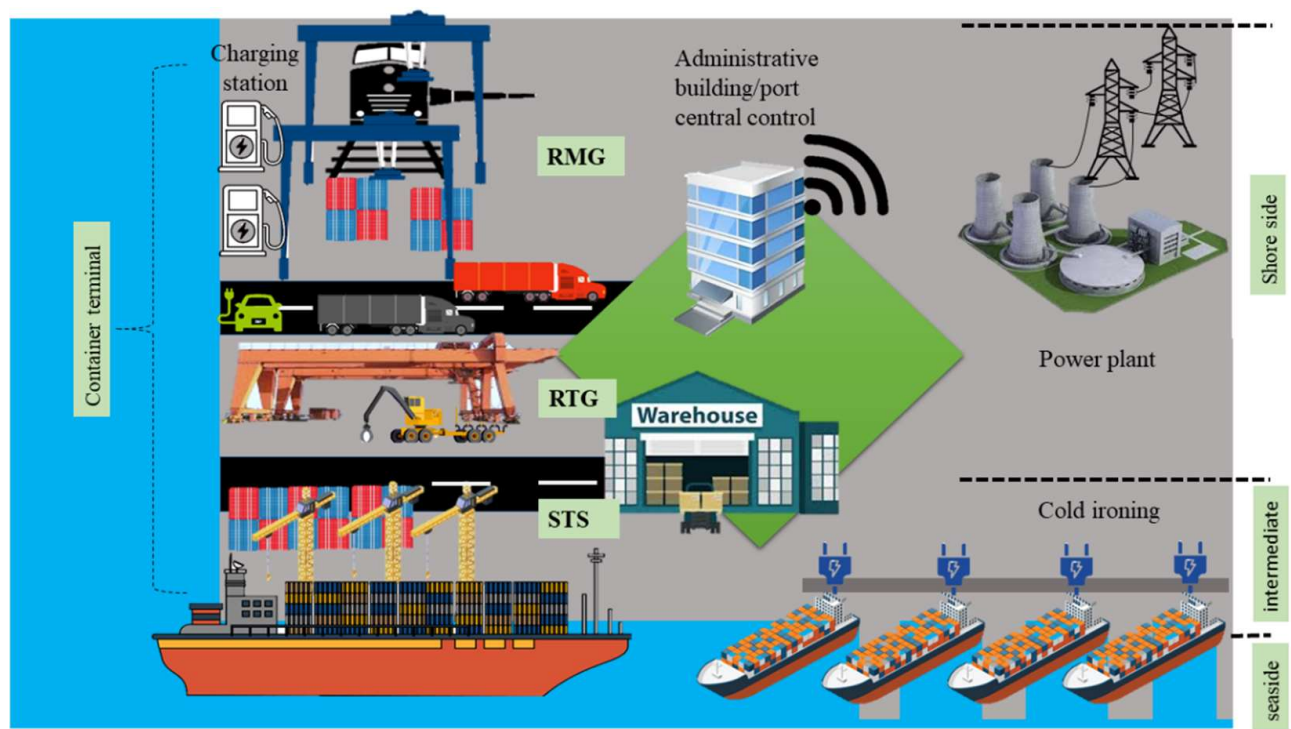

Figure 3. Seaport activities and load components. (Abbreviations: Rail mounted gantry (RMG), rubber tyred gantry (RTG) and ship to shore (STS))

Loads on the shore-side: On the shore side, administrative buildings, a custom facility, as well as a warehouse for goods are built. In this infrastructure, electricity is consumed mostly for lighting, Heating, Ventilation, and Air Conditioning (HVAC) system and equipment [14]. Many factors influence a building's energy consumption behavior, including weather conditions, building materials, occupant behavior, work durations, equipment, and electrical load used [15].

In terms of transportation, different land vehicles such as trucks, cranes, yard tractors, and trains are powered by diesel fuel, and electricity is needed for electric vehicles (EVs) charging stations. Typically, diesel is used as the primary source for motor movement in the cranes. However, recent researches on electrical cranes show a lot of interest in energy storage systems to store the potential energy regenerated from lowering and lifting cranes operations [16].

Loads on the seaside: The seaside is where a marine vessel or any watercraft transportation voyages across the ocean that serves the purpose of carrying passengers or delivering cargo. Ships will make more voyages, consume more fuel, and increase the density of water traffic as global trade expands. Normally heavy fuel oil (HFO) is consumed for big vessels and bulk carriers. General cargo vessels consume the most HFO, followed by oil tankers and cruise ships accounting for $66,000 \mathrm{t}, 43000 \mathrm{t}$, and 25,000 $\mathrm{t}$ of HFO consumption, respectively [17]. The spill of fossil-based marine fuel into the water and its combustion into the air become a major threat to the environment [18]. Despite its undesired environmental impacts, HFO continues to be the preferred fuel of the maritime transport industry due to its relatively low cost, widely available resources, and the ability to suit engines that were originally designed for HFO [17].

In order to prevent from heavy utilization of HFO and being along with port development, ships technology emerging toward electrification concept by implementing Integrated Power System (IPS) and storage system known as All Electric Ship (AES) [19]. Energy usage for a vessel is hard to measure as it depends on numerous aspects such as the size of the vessel, the onboard loads, vessel speed, sea waves, and weather conditions.

During berthing for transit or transferring goods, the auxiliary engines of the ships are kept on to supply the energy for onboard loads [20]. To overcome continuous fossil fuel burning, cold-ironing facilities are provided at the intermediate area between the sea and shore side. Power requirement varies from $300 \mathrm{~kW}$ to $7 \mathrm{MW}$ depending on the type of ships and berthing duration [21]. In addition to the onshore power supply, the port 
must accommodate the shore charging facilities. Some of the vessels with storage components such as hybrid vessels and AES will need a charging station in the port area for recharging their batteries and supply onboard loads.

Loads in the intermediate area: In the intermediate area, besides cold ironing and charging stations, there are container terminal facilities for loading/unloading cargo and transshipped the goods for the next transportation [22]. The container terminal is an important part of international logistics and requires a large amount of energy, both fuel, and electricity [23]. Container terminals serve three primary functions: yard side, quayside, and landside [24]. Each side has its operation and transportation. Cold storage facilities among the terminal operation consume a lot of energy, as it is a temperature-controlled storage solution for perishable goods. Port of Wilmington built a 101,000 square foot refrigerated warehouse to refrigerate food, pharmaceutical, floral, and other items that require maintaining specific temperatures for the storage [25]. It allows distribution companies to deliver their goods locally, nationally, and globally in a good condition.

In container terminal, there are various types of cranes in use, from ship to shore (STS)/quay cranes (QC) to automated guided vehicles (AGVs)/automated straddle carriers (ASCs) and finally, rail-mounted gantry (RMG) cranes before they are transferred into truck/trains [26]. Considering peak power demand, cranes need about $72 \%$ of total energy (STS cranes about 37\%, ASC cranes 32\%, and RMG around 3\%) [27]. The breakdown of the cranes' power demand is shown in the pie chart below.

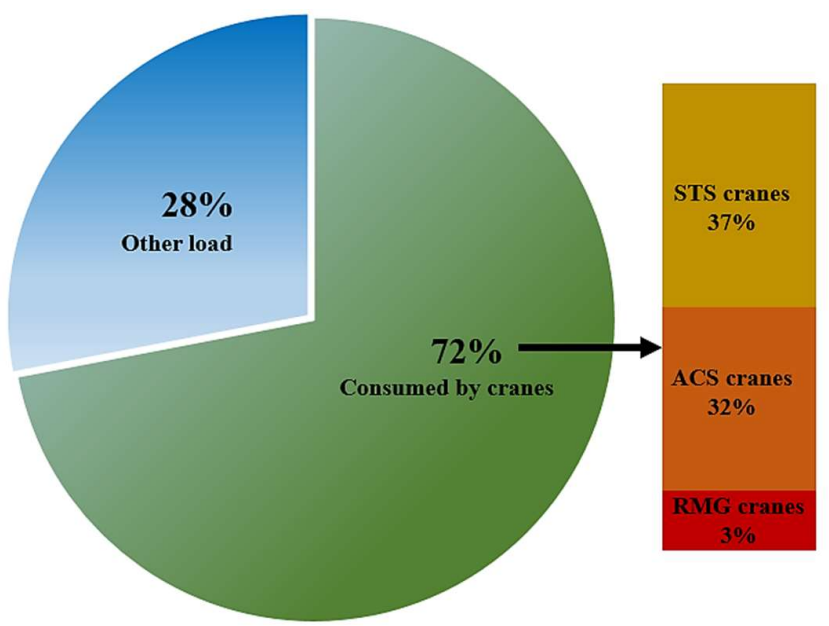

Figure 4. Break down of cranes power demand during demand peak intervals.

From the appliances that are used and activities conducted within the marine port, it can be seen that the seaport sector has a large energy demand that makes the energyhandling problem a complex task. Hence, a robust power system is required that can provide sufficient energy supply to all distribution loads. Any shortcoming in energy delivery will cause a big disruption to the seaport operations.

Therefore, it is very important to distinguish between the critical and non-priority loads so that during emergency situations the critical loads will be the priority to get the energy supply [28]. Table 2 summarizes the findings regarding seaport-related services and their load. 
Table 2. Seaport activities and loads variation [5][29].

\begin{tabular}{|c|c|c|c|c|}
\hline $\begin{array}{l}\text { Seaport's } \\
\text { services }\end{array}$ & Load & $\begin{array}{c}\text { Factor influence energy } \\
\text { consumption }\end{array}$ & $\begin{array}{l}\text { Load } \\
\text { classifications }\end{array}$ & Form of energy \\
\hline Vessel & $\begin{array}{l}\text { Passenger ships } \\
\text { (cruise, ferry), } \\
\text { container ships, } \\
\text { electric ships, tugs, } \\
\text { gliders, bunkers, boats, } \\
\text { tankers, hovercraft, } \\
\text { sailboats, submarines, } \\
\text { yachts }\end{array}$ & $\begin{array}{l}\text { Size of the ship, activity } \\
\text { conduct on the ship, } \\
\text { time of operation, } \\
\text { weather, wave, speed }\end{array}$ & \multirow{6}{*}{$\begin{array}{l}\text { 1)Peak load } \\
\text { 2)Critical load } \\
\text { 3)Non-critical } \\
\text { load } \\
\text { 4)Variable load } \\
\text { 5)Constant load }\end{array}$} & \multirow{6}{*}{$\begin{array}{l}\text { 1)Electricity } \\
\text { 2)Fossil fuel }\end{array}$} \\
\hline $\begin{array}{l}\text { Goods } \\
\text { handling }\end{array}$ & $\begin{array}{l}\text { Cargo, container, } \\
\text { quay, logistic, freight } \\
\text { forwarder, customs } \\
\text { warehouse, storage, } \\
\text { security, loading- } \\
\text { unloading }\end{array}$ & $\begin{array}{c}\text { Number of cranes, } \\
\text { amount of cargo, hours } \\
\text { of operation }\end{array}$ & & \\
\hline Administration & $\begin{array}{l}\text { Management and } \\
\text { administrative } \\
\text { building, planning, } \\
\text { service solution, IT, } \\
\text { monitoring } \\
\end{array}$ & $\begin{array}{c}\text { Type of electrical } \\
\text { equipment, weather, } \\
\text { building material, hours } \\
\text { of operation, occupant } \\
\text { behavior }\end{array}$ & & \\
\hline Transportation & $\begin{array}{c}\text { Electric vehicles, } \\
\text { cranes, trucks, yard } \\
\text { tractors, trains }\end{array}$ & $\begin{array}{c}\text { Number of } \\
\text { transportation, hours of } \\
\text { consumption }\end{array}$ & & \\
\hline Electric Facility & $\begin{array}{c}\text { Cold ironing, charging } \\
\text { station for electric } \\
\text { vehicles }\end{array}$ & $\begin{array}{c}\text { Time of berthing, } \\
\text { number of ships per } \\
\text { berthing, size, and } \\
\text { ship's load }\end{array}$ & & \\
\hline Maintenance & $\begin{array}{l}\text { Repair and } \\
\text { maintenance }\end{array}$ & Type of the maintenance & & \\
\hline
\end{tabular}

\subsection{Port critical concerns and green maritime policy}

The urgent need for a more efficient maritime system demands a great effort to increase the performance of every subsystem linked to it by implementing an energy efficiency program. Many of the ports collaborate with the national institutional running the research in the energy management strategy. It is critical to identify the root of the problem and core issues in the port to achieve a good outcome from the planning.

The European Sea Ports Organisation (ESPO) in their latest report (October 2020) highlighted the top ten priorities of the port sector from 1996 to 2020 [30]. Figure 5 shows the top three ports issues from 2009 until 2020. As it can be seen in this data, most of the issues listed have remained the same while their relative positions have changed over time. However, air quality and energy consumption remained mostly the highest priorities. This data is important as it identifies the vital concerns that port managing sectors are working on.

According to the top three priority issues highlighted in Figure 5, air quality has persisted as number one from 2013 until 2020 followed by energy consumption. The problem arises from the fact that air quality, noise, port waste, and climate change are strongly related to environmental concerns. This indicates that environmental issues are big problems in the port sector that need immediate action. Without a fast action, the emissions from maritime transportations are predicted to rise by $250 \%$ from the amount released in 
2012 [1]. Heavy utilization of fossil fuel in marine transportation and other areas contribute to serious air pollution from Carbon Dioxide (CO2) and greenhouse gas (GHG) emissions. This is because the fossil sources encompass hazardous content; which burning it, will emit chemical and dangerous gases such as Particulate Matter (PM), CO2); Sulphur Dioxide ( $\left.\mathrm{SO}^{2}\right)$; Nitrogen Oxides (NOx); and Black Carbon (BC) to the air [31]. Consequently, this emission results in the acid rain and serious climate changes. It is also capable to reach up within $400 \mathrm{~km} \mathrm{[32]} \mathrm{of} \mathrm{the} \mathrm{land} \mathrm{and} \mathrm{give} \mathrm{the} \mathrm{negative} \mathrm{effect} \mathrm{on} \mathrm{human} \mathrm{health}$ like asthma, tuberculosis, impact on children's lung growth, cardiovascular disease, and lung cancer.

\begin{tabular}{|c|c|c|c|c|c|c|c|}
\hline & 2009 & 2013 & 2016 & 2017 & 2018 & 2019 & 2020 \\
\hline 1 & Noise & Air quality & Air quality & Air quality & Air quality & Air quality & Air quality \\
\hline 2 & Air quality & $\begin{array}{l}\text { Garbage/ } \\
\text { Port waste }\end{array}$ & $\begin{array}{c}\text { Energy } \\
\text { consumption }\end{array}$ & $\begin{array}{c}\text { Energy } \\
\text { consumption }\end{array}$ & $\begin{array}{c}\text { Energy } \\
\text { consumption }\end{array}$ & $\begin{array}{c}\text { Energy } \\
\text { consumption }\end{array}$ & $\begin{array}{l}\text { Climate } \\
\text { change }\end{array}$ \\
\hline 3 & $\begin{array}{l}\text { Garbage/ } \\
\text { Port waste }\end{array}$ & $\begin{array}{c}\text { Energy } \\
\text { consumption }\end{array}$ & Noise & Noise & Noise & $\begin{array}{l}\text { Climate } \\
\text { change }\end{array}$ & $\begin{array}{l}\text { Energy } \\
\text { efficiency }\end{array}$ \\
\hline
\end{tabular}

Figure 5. Top three issues in the port from 1996 to 2020 [30].

Meanwhile, the ports energy consumption aspect is increased due to various reasons. Development and expanded port functionalities over time rising the energy demand from many facilities and loads varies with low and heavy consumption. Continuously heavy use of energy will cause fast energy resources depletion. The inequality between energy production and the demand leads to frequent unplanned power outages. Poor power quality, lack of energy monitoring, and old instruments are also among the factors that cause the high energy consumption problem resulting in additional energy costs in ports' daily operation. The need for improvement both in infrastructure and port power system will acquire a huge amount of investment. Lacking of proper planning and a solid development framework will cause great losses. Based on these scenarios, three major issues related to seaports are energy, environment, and cost as shown in Figure 6.

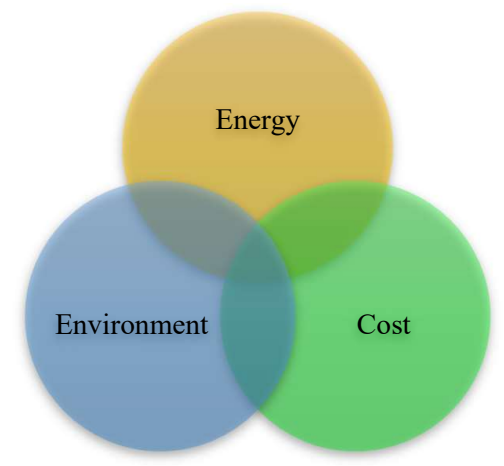

Figure 6. The three vital issues in the maritime sector.

Due to the serious environmental impacts caused by the pollution from marine logistics, ports are moving toward a greener industry by implementing various alternatives. Particularly in recent years, the arising awareness on environmental issues has made this target one of the compulsory goals in achieving high-energy efficiency levels. Authorities have formulated ports policies consistently with tight regulation to ensure the minimum GHG emission. 
Port authority is a party who governs the marine area typically established by legislative bodies responsible to manage ports and acts as policymakers [33]. In most countries, they can be public or partial-public organizations in charge to develop the port by planning the wide-ranging infrastructure, maintenance and ensuring the port development is in line with the regulation [34]. Environmental policy is a medium to improve for the healthier atmosphere encouraging any option or step taken is based on the regulation [35]. Corresponding to this, International Maritime Organization (IMO) in the latest regulation, limits the sulfur content in fuel to $0.5 \% \mathrm{~m} / \mathrm{m}$ known as 'IMO 2020' [36]. The changing in sulfur limitation from 2000 to 2020 is displayed in Table 3. This new rule is to comply with an amendment to Annex VI of the International Convention for the Prevention of Pollution from Ships (MARPOL). The five focus outcomes from IMO 2020 are: 1) Cleaner air, 2) Higher quality fuel, 3) Positive impact on human health, 4) Ship operator role, and 5) Changes for enforcement authorities.

Table 3. Marpol Annex VI Fuel Sulfur Limit

Source: Marpol 2018

\begin{tabular}{|c|c|c|}
\hline \multirow{2}{*}{ Date } & \multicolumn{2}{|c|}{ Sulfur limit in fuel $[\% \mathrm{~m} / \mathrm{m}]$} \\
\cline { 2 - 2 } & SO ECA & Global \\
\hline 2000 & 1.5 & 4.5 \\
\hline 2010 & 1.0 & \\
\hline 2012 & & 3.5 \\
\hline 2015 & \multirow{2}{*}{0.1} & \\
\hline 2020 & & 0.5 \\
\hline
\end{tabular}

Besides, World Ports Climate Initiative (WPCI) through Word Ports Climate Declaration in 2008 and the European Sea Ports Organization (ESPO) with their Environmental Code and Green Guide provided strict ideologies and guidelines [37]. In line with the green port objective, the Port Authority of Genoa (GPA) is developing a plan integrating renewable energy in their marine sector known as Port Energy Environmental Plan (PEEP). The ultimate goal of the PEEP, intended, to reduce 20000t of CO2 annually by utilizing 12 plug cold ironing facilities, wind turbines, and photovoltaic power station with an overall investment of 60 million Euros [38]. Recently, in Jan 2021, the International Association of Ports and Harbors (IAPH) has signed a contract with the Green Award Foundation to rule the Environmental Ship Index (ESI) [39]. This program allows the shipowners and ports to go green by using cleaner engines and fuel. ESI embraces the vessels' Nitrogen Oxide (NOx) and Sulphur Oxide (SOx) emissions. From ESI, a vessel indicates the fuel efficiency improvement over time and dropping the carbon dioxide emissions.

To move towards a healthier environmental space, ports must plan and manage their operations and future potential expansion (growth) in a sustainable manner. Saeyeon Roh et al. [40] in their research state that the majority of the existing literature emphasis is on the environmental aspects for sustainable development but they fail to clarify what factors influence this process. Several authors studied the causes that contribute towards air pollution and environmental damage from the operation of the harbors. Bunkering from the vessels generates the risk of oil spill with potentially disastrous impacts on beaches' food chains [41]. Matishov and Selifonova [42] point out that the source of water resources damage comes from a high density of ship transportation via waterborne traffic. Meanwhile, Brigitte Behrends and Gerd Liebezeit [43], address that the two leading destructive factors generated by shipping movement are atmospheric and seawater contamination. Diesel from the ship releases unwanted content to the atmosphere such as NOx, CO2, SOs, etc. In an attempt to safeguard the nature and waterway, several legislation for future growth of port and its construction in both international and domestic level are released from time-to-time aiming to handle environmental issues based on strict standards into 
core port's strategies. For instance, legislation in a few countries are listed in Table 4 below [40];

Table 4. List of legislation in a few country.

\begin{tabular}{|c|c|}
\hline Country & Legislation \\
\hline EU & $\begin{array}{l}\text { Classification Societies - Regulation (EC) No } \\
\text { 391/2009, Ship-Source Pollution - Directive } \\
\text { 2000/59/EC, Marine Equipment - Directive } \\
\text { 96/98/EC and Directive 2014/90/EU }\end{array}$ \\
\hline Australia & Environmental Protection Act 1986 (WA) \\
\hline $\begin{array}{l}\text { New } \\
\text { Zealand }\end{array}$ & $\begin{array}{l}\text { Resource Management (Marine Pollution) } \\
\text { Regulations }\end{array}$ \\
\hline USA & Diesel Emission Reduction Act (DERA) \\
\hline Singapore & $\begin{array}{l}\text { Environmental Protection and Management } \\
\text { Act (Cap.94A) }\end{array}$ \\
\hline
\end{tabular}

Without a doubt, all of this environmental legislation offer vast advantages in terms of health, clean air, economy, energy, and potential for the new technology if it is properly considered in the port planning. Nevertheless, the great challenge is that all the planning steps must be compatible with the rules, from the initial step of Research and Development, collecting real time data, collaboration among the parties, implementing, monitoring, and analysis. All of these stages are time-consuming and involve with high capital investment where payback period analysis is necessary. Cost is one of the main drivers to run all the strategy planning. Because of this risk, the relevant parties especially ports themselves are reluctant to implement any environmental program.

\subsection{Seaport energy revolution}

\subsubsection{Conventional system}

In the beginning phases of the maritime system, there has been no concern for energy because it was solely utilized for shipping transportation. When the industrial revolution arrived, the energy demand began arising. Electricity and fuel are the two main forms of energy used in this sector. Depending on the availability and variation of the primary sources in a particular country, both electricity and fuel are produced from fossil-based sources (coal, oil, and natural gas). A power plant is a network facility that generates electricity and delivers it to end-users. It consists of generation, substation, transmission, and distribution. Electricity is not freely available in nature, so it must be produced by transforming the primary energy to electricity through a process. Figure 7 displays the entire power station network, from generation to the seaport.

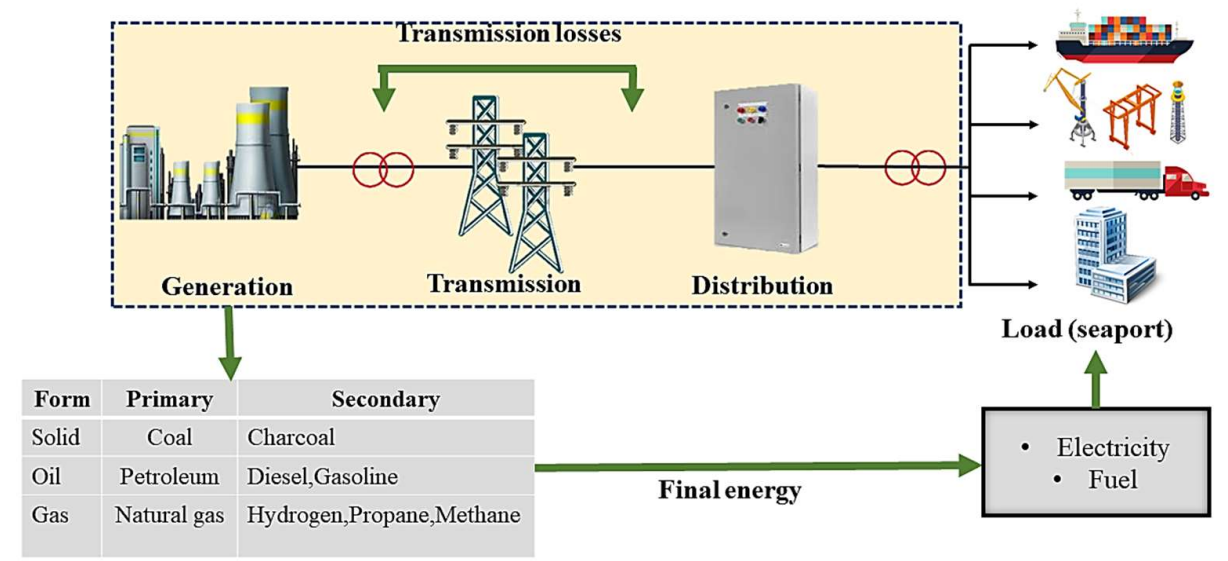

Figure 7. The overall framework of the conventional structure. 
In the 1880s, coal was first used to generate energy and became a fundamental driver of steamships [44]. It is a combustible black rock that has been formed over million years by the decay of land vegetation and generates energy under high pressure. Coal is convenient to use because it is easily combustible, and cheaper. Apart from electricity, another fundamental energy, particularly for maritime transportation, is fossil fuel, which contains hydrogen and carbon in its particles. Because of the ship's speed improvement and variety of benefits provided by oil engines, British Admiralty decided to convert its fleet of warships from coal to oil propulsion in 1912 [45]. Indeed, fuel oil has become the primary source for transportation, with all modes of transportation are reliant on refined petroleum products such as gasoline for automobiles, diesel for trucks, and bunker fuel for maritime shipping. All of these transportation modes are used during the distribution of goods and cargo. In the United States, gasoline is the most consumed petroleum product [46]. Diesel, on the other hand, is more durable, has a higher energy density, is thicker, and is more efficient than gasoline [47].

Previously, many vessels, particularly those with bunker fuel, used Heavy Fuel Oil (HFO) to allow the ship propeller or alternator to be rotated. This can be accomplished by either burning fuel in the engine combustion chamber or producing steam in the boiler. Because of its relatively higher density and low cost, HFO is a preferable marine fuel source. HFO is viewed by its heavy molecules containing long-chain hydrocarbons, density greater than $900 \mathrm{~kg} / \mathrm{m} 3$ at $15^{\circ} \mathrm{C}$, and kinematic viscosity greater than $180 \mathrm{~mm} 2 / \mathrm{s}$ at $50^{\circ} \mathrm{C}$ [48]. The HFO comes in three varieties listed in Table 5:

Table 5. Three variants of hfo and their sulfur content [36].

\begin{tabular}{|l|l|c|}
\hline No & \multicolumn{1}{|c|}{ Variant } & Sulfur content \\
\hline 1 & High Sulfur Fuel Oil (HSFO) & $3.5 \%$ \\
\hline 2 & Low Sulfur Fuel Oil (LSFO) & $1.0 \%$ \\
\hline 3 & Ultra Low Sulfur Fuel Oil (ULSO) & $0.1 \%$ \\
\hline
\end{tabular}

The sulfur content is a key differentiator between these three types of HFO. However, from $1^{\text {st }}$ January 2020, HFO can only be used by vessels equipped with exhaust gas cleaning systems (EGCS), and IMO has set new regulations banning vessels from using fuels that have sulfur substances above $0.5 \%$ [36]. Due to the tight prohibitions, HSFO and LSFO are no longer practical options for marine transport. The only choice to comply with this limit is ULSO, which has a sulfur content of $0.1 \%$. Unfortunately, the desulfurization process of heavy fuel oils requires a very high cost and is not economical anymore.

Even though electricity and fuel are greatly used in the seaport sector since its early stages of development but due to the arising issues, there is a great interest in alternative solutions. This alternative is by considering electrification of vehicles, cold ironing systems, alternative fuels (i.e., LNG, biofuels, methanol, hydrogen, and low-sulfur fuels) and implementation of both renewable energy and energy storage through implementing the microgrid power systems.

\subsubsection{Ports and ships electrification}

Electrification is the process of using electricity to power a device. From the seaport perspective, electrification can be viewed as the replacement of fossil fuel-based energy with new advanced technologies through the use of electricity. Marine transportation contributes significantly to air pollution and climate change mainly for two reasons: 1) port is the area where emission sources are least regulated and 2) high reliance on fossil fuels. With the increasing number of ships, the ports' energy management is required to provide sufficient power to supply the ship during berthing. Large ships have a power range between $1 \mathrm{MW}$ to $6 \mathrm{MW}$ [49]. While the main engines are normally turned off during berthing, the vessel's auxiliary engines are turned on to supply power to all loads inside the vessel such as lighting, ventilation, cooling and other onboard equipment. A study 
on different types of vessels in Ref [21] shows that the average berthing time per vessel is between 21 hours -52 hours. The burning diesel oil during berthing in such a long time inject severe GHG emission.

To resolve this problem, shore-side electricity practice or well known as cold ironing is introduced to mitigate undesirable environmental impacts at seaports. Employment of this technique allows a ship to shut off the auxiliary engines when docking and receiving the electricity supply from the shore to maintain the entire load in the ship. It gives substantial advantages by reducing the dependency on fossil fuels and lessen the GHG emission to the air. The energy required for the cold ironing can be supplied directly from the utility grid, RESs, and ESS. Alexander Innes and Jason Manios [50] in their publication highlighted a few ports around the world that already utilized cold ironing. Despite the promising benefits of a cold ironing system, many ports, particularly small ports, do not install it due to a few constraints. To overcome this, alternative power sources are formed by using shipboard microgrid (SMG) where this method acts as mobile cold ironing facilities by sharing power from multiple ships in port [51][20]. Another innovative solution with the same concept is known as vehicle-to-grid (V2G) and boat-to-grid (B2G) paradigms [52][53][54].

However, with the high energy requirement for the entire port operation, reliance on the power from the grid alone is not enough. Thus, the port industry has started to explore clean energy resources including renewable energy. A few ports even built their renewable energy power plant. Currently, Jurong Port is the world's largest port installing solar power generation facility, estimated to generate more than $12 \mathrm{mil} \mathrm{kWh}$ of solar energy per year which covers $60 \%$ of the port power demand [55]. In addition, it also does help to reduce 5200 tones carbon emissions in a year. Meanwhile, Aalborg Port, Denmark not only constructed solar cell systems with an annual production of $80000 \mathrm{kWh}$, but also purchased port facilities at Nordjylland Power Station which a $2 \mathrm{MW}$ wind turbine is included in the deal [56].

Utilizing multiple RES and the need for a storage solution, smart technologies such as a microgrid system are being introduced. Microgrid's alternative is great at solving power supply problems and it has been gaining more attention lately. The interest in microgrids is increasing due to their promising advantages in providing sustainable, reliable, efficient, and environmentally friendly power supply [57]. Market acceptability of microgrid technologies due to their reliability and cost-efficient power supply makes them a practical and effective solution in power delivery. Although microgrids have been widely developed around the world but their application in harbor areas remained limited. Due to this situation, the development of a microgrid in a port presents significant challenges. Diversity of loads in the seaports (cranes, ship, container, cold ironing, building, etc) gives the difficulty in load forecasting and accurate measurement of power requirement. To avoid prohibitive costs and inefficient system, a comprehensive study on ports microgrids planning, energy management, regulation, and other aspects is required.

In addition to the microgrid power system, ships as one of the large energy consumers at ports need to be transformed from a high carbon-based power consumption (fossil fuel) to a low carbon-based power consumption unit by deploying alternative clean fuels such as LNG, hydrogen, and biofuel. From the policy aspect, the pressing issue confronting by ship-owners is the International Maritime Organization's MARPOL ANNEX VI tier III air pollution regulations, which was set to go into effect in 2016 [58]. This issue is getting worse as many existing ships are aged and have inefficient auxiliary engines. As a result, more diesel fuel is consumed, escalating air pollution and higher noise levels within the harbor.

Along with the industrial developments and innovations in power systems, ship transportation is also emerging toward the All-Electric Ship (AES) concept [59][60]. Conventionally, ships used a steam turbine as a prime mover, but in 1850, it switched to steam piston engines [61]. The ship's electrification began with an integrated power system (IPS) that uses electric propulsion. It gradually evolved into the hybrid power system (HPS) by incorporating energy storage elements. S. fang et al [62] in their research, modelling the 
next version of AES by using photovoltaic sources. The goal is to provide better energy production through a hybrid concept that combines diesel generation with renewable sources.

\section{Seaport microgrid}

Implementing a microgrid system is advantageous to the seaport because the port's geographical location can provide a strong base for RES production. With the microgrid system, the generation does not depend on fossil-based energy resources anymore but also encompasses the production from alternative energy resources as well such as clean energy and RESs. In European countries, wind turbine installation gradually increases to achieve fossil-free electricity. Denmark's largest offshore wind farm, Kriegers Flak in the Baltic Sea, was recently built, with a 600MW capacity, capable of supplying 600,000 Danish households [63][64]. 72 units of wind turbines were installed with an estimated investment of a maximum of $€ 1.3$ billion contribute significantly to renewable energy in the Nordic region [63][65]. The constant breezes and bluster of the climate in this country make wind turbines practical and well established.

Furthermore, a port is an area with a large flat surface that is suitable for solar panel installation such as, the rooftop of a warehouse, a storage area, or a flat roof from a building. However, such infrastructure may not always be appropriate for large-scale solar energy utilization. Aside from wind and PV, some ports utilized other forms of energy such as waves (e.g. Port Kembla in Australia), tide differentials (Port of Digby, Nova Scotia), and geothermal energy (Hamburg) [38]. Thus, seaport microgrids appear to be a feasible option for the future power system in the harbor area.

Thereby, it is important to understand the significant aspects of this research field. VOSviewer is a visualization tool that is useful for mapping large co-occurrence keywords from the research sources especially from Web of Science and Scopus databases [66]. With the assistance of such visualization tools, evolutionary patterns of seaport power systems can be easily interpreted in order to identify the trends and potential future research directions from a macro perspective to the most co-occurrence research. It will enhance understanding of the research field in the seaport microgrids and provide an intuitive overview. Figure 8 shows the co-occurrence analysis of the maritime field with the search keywords of (microgrid* AND (seaport* OR "Maritime" OR marine OR ("Ship Harbor"))) from Scopus database. The larger nodes indicate that more papers have been published in that area showing the research field is trendy. Small nodes in the network show low cooccurrence of keywords that might be because the topic is still new, providing the opportunity for further research. In this case, larger nodes in Figure 8 represent 'microgrid/microgrids/ship' keywords. It indicated that microgrid power system are increasingly popular in the maritime sector. Meanwhile, the keywords from the small nodes reflect that researchers from all over the world are engaged in marine power systems, including energy management, optimization, energy efficiency, and other power-related subject areas. Since small nodes is caused by low co-occurrence, this allowing more research opportunity for the improvement for better marine power system. 


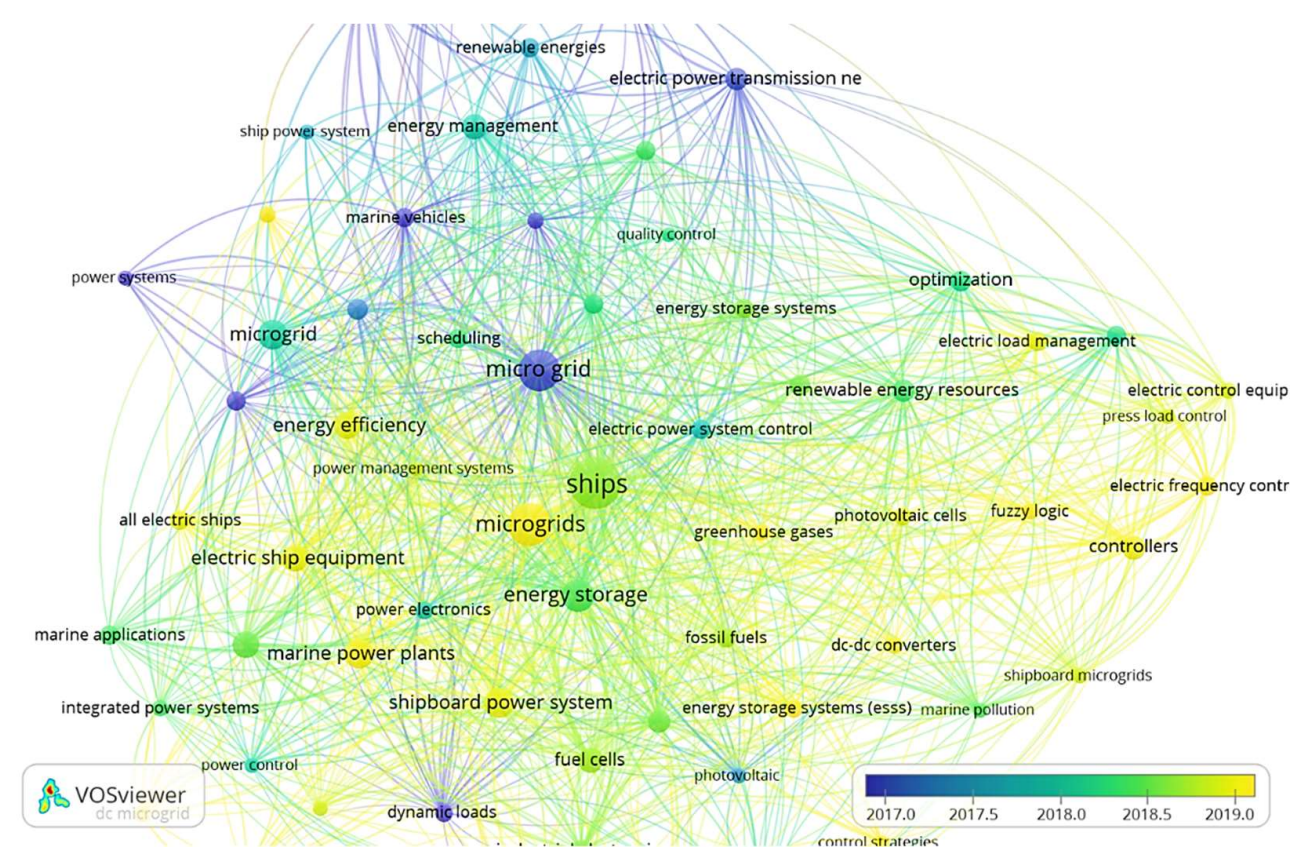

Figure 8. VOSviewer visualization for co-occurrence keyword from recent Scopus research publication on the harbor power system (Accessed on 20 July 2021).

\subsection{Seaport microgrid topology}

A microgrid typically has a component of distributed energy resources (DERs) that can be a generator or RES, ESS, power converters, and loads [67]. It links the low voltage (LV) or medium voltage (MV) network to the utility grid at a single point known as point of common coupling (PCC) [68]. Microgrids operate the same way as the main grid but with the special ability to connect or disconnect from the grid. In the utility power industry, microgrid system is beneficial in both situations. Thus, this power system is mainly working in two mode of operation namely; 1) grid connected and 2) island mode [69][70].

During grid-connected mode with the main grid fully functional, the microgrid acts as an extension part of generator by supplying power to the utility grid. However, it can also absorb power from the grid. The inconsistency of power generation from RESs can sometimes produce an abundance of power that exceeds the microgrid's energy demand, thereby providing an opportunity to sell energy back to the main grid and make a profit [71]. Huang et al. [72] considered 'market-based time-of-use (TOU) pricing' strategies for a microgrid to reduce the cost of electricity from a utility. Interestingly, it can operate independently as an autonomous power system during the island mode to give power support at times of stress due to several circumstances [73]. Microgrids help in power restoration after the occurrence of a failure on the utility side, ensuring that end consumers have continuous access to energy, particularly for critical loads. Utility failures can occur as a result of an unplanned shutdown due to the fault, or when power demand surpasses power generation [74][75].

Basically, microgrids frameworks can be classified into three topologies, which are; 1) AC microgrids, 2) DC microgrids, and 3) hybrid AC/DC microgrids [76][68][74]. In AC microgrids, the common bus is AC bus where DC-to-AC inverters are needed for ESSs 
and DC generating units (PV and fuel cell). Meanwhile, AC-to-DC rectifiers are normally used for supplying DC loads. However, for DC microgrids, the common bus is in DC that requires $\mathrm{AC}$-to-DC rectifiers for $\mathrm{AC}$ generating components and $\mathrm{AC}$ loads are supplied via DC-to-AC inverters. In the case of hybrid microgrids, both types of buses exist in the same network. It allows the flexible connection of DC and AC components to their bus accordingly and reduces unnecessary converters. Figure 9 shows all three topologies and their basic network connections.

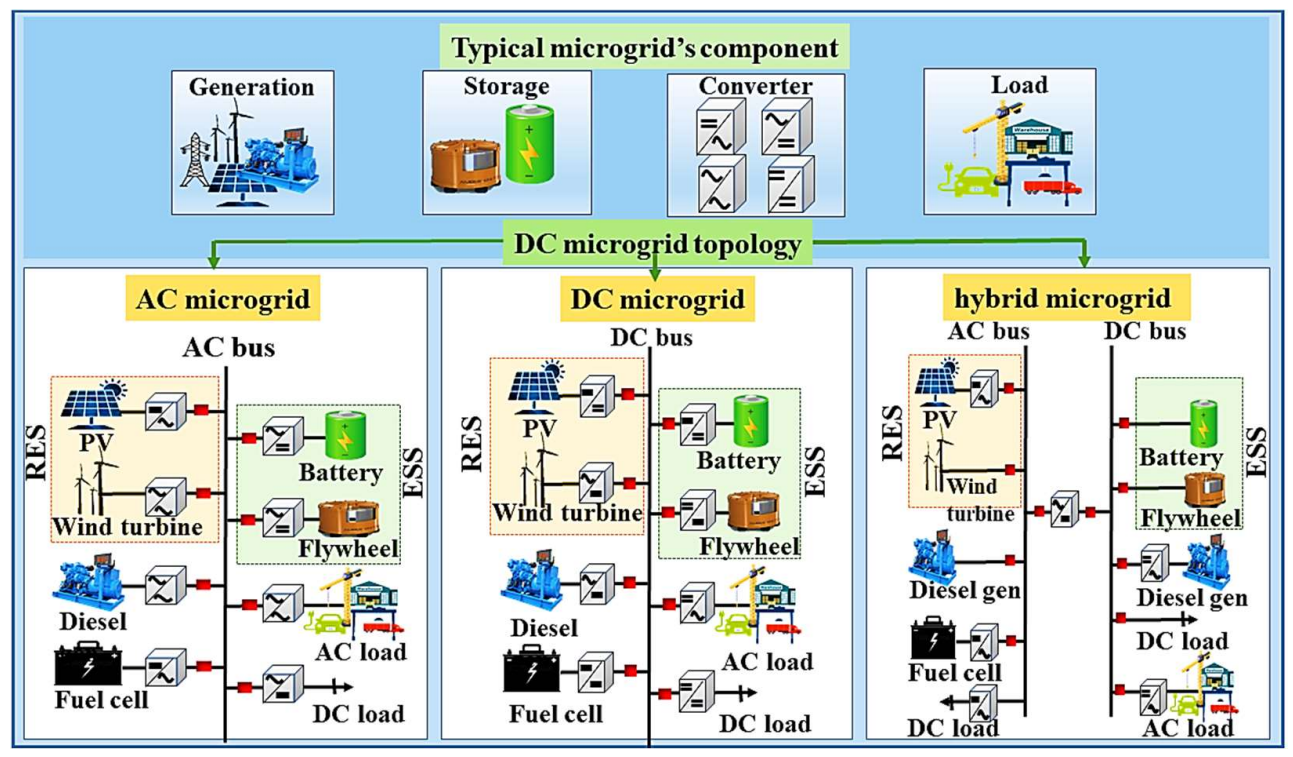

Figure 9. Microgrid topology options for a seaport.

The AC topology is the most commonly used topology that has become the standard choice from the early phase of microgrid invention due to its ability to be synchronized with the AC distribution network, simple structure, and economic viability [68]. Normally, when a microgrid has a connection with the main utility, AC microgrids become an ideal choice. It has the capability to transmit the power over a long distance, is easy to adjust the AC voltage into different levels for various applications, and is applicable for induction motors. Despite all of these benefits, long-distance transmission lines are one of the barriers that make it cost-ineffective and impractical in some cases.

However, if the microgrid system is completely isolated without connection to the grid, DC microgrids happen to be the preferred option. The advancements of power electronics technology have resulted in arising the number of DC loads, indicating that modernization of the existing energy system is inevitable [77]. Continuously using AC configuration will require a lot of converter for DC applications and reduce the microgrids' efficiency [78]. In addition, encouragement toward storage systems and clean energy resources such as PVs in power systems, which are in DC, oblige better coordination for the distribution network. As a result, DC microgrids have drawn a lot of interest in the research community to grant a direct connection with DERs, ESSs, and DC loads through the DC bus and decrease the impact on the AC networks. DC distribution systems are now gradually used for various applications such as aircraft, automotive, 
marine, and manufacturing industries [79][80]. Z. Jin et al. [81] investigate the combination concept from DC microgrids with a maritime onboard power system for AES. In the maritime sector, the adoption of DC topology brings an enormous range of advantages to the onboard power system by eliminating the frequency constraint, allowing utilization of high-speed generators, and providing systematic management [81]. R. Prenc et al. [82] stated that DC ship power systems in the maritime sector prevailed over the AC systems due to the following reasons; 1) improvements in prime mover performance and fuel cost savings, 2) reduction in weight and space, 3) unity power factor for generators, 4) low transmission losses, 5) faster and easier parallel connection of generators, 6) flexible and simple implementation of ESSs.

Both AC and DC microgrids, however, rely on the converter when they interact with the opposite network source that attaches to the buses, resulting in unavoidable power losses during the conversion process [76]. Accordingly, a hybrid AC/DC microgrid seems like a flexible solution for integrating AC or DC-based components while reducing reliance on converters. The reduction in conversion equipment improves overall system efficiency and reliability whilst also lowering ongoing costs [83]. X. Liu et al. [84] look into different operating modes of hybrid microgrid and apply coordination control schemes to produce maximum power from RES, reduce power transfer between AC and DC networks, enhance stabilization in operation with various networks of DER, ESS and load components.

By the presence of two types of buses in a hybrid microgrid, the control, operation, and management become more complex compared to the individual AC and DC microgrids. Furthermore, the exploration of hybrid microgrids is still in its formative development and requires extensive research. Table 6 gather the reference of research publication that apply three kinds of microgrid topology into seaport application.

Table 6. Seaport application with different topology.

\begin{tabular}{|c|l|l|}
\hline Topology & \multicolumn{1}{|c|}{ Seaport application } & \multicolumn{1}{|c|}{ References } \\
\hline AC & Shipboard microgrid & {$[85][86][87][86]$} \\
& Cold ironing & {$[88]$} \\
\hline DC & Ship-based seaport microgrid & {$[20][51]$} \\
& Shipboard microgrid & {$[85][89][90][91][92]$} \\
& Cold ironing & {$[93]$} \\
& Electric ship & {$[94]$} \\
& Offshore application & {$[95]$} \\
\hline Hybrid & Electric ferry shipboard & {$[96]$} \\
AC/DC & Shipboard microgrid & {$[97]$} \\
& Cranes & {$[26]$} \\
& Cold ironing & {$[98]$} \\
\hline
\end{tabular}

\subsection{Conceptual seaport microgrids in shore side and seaside.}

\subsubsection{Shore side}

Conventionally, the relationship between a seaport and ships mainly corresponds to logistic activities. The electrification innovation in the maritime sector represented by; 1 ) seaport microgrid and 2) all-electric ship (AES) is the promising solution toward achieving 
zero carbon footprint in future seaports [62]. Apart from the logistic side, the rising electrification trend in this sector extended the connection of seaport-ships to the electric side. With the broadened infrastructure and multiple functions conducted in the port area, a large amount of energy is necessary to run their operation. Due to this situation, the maritime sector facing the problem of power shortage and an environmental catastrophe. These constraints encourage the incorporation of RES and ESS into the seaport power system, further complicating its control and management. Therefore, the concept of seaport microgrid is introduced to provide better coordination for the multiple energy resources, storages, and variation in seaport loads [99]. Figure 10 illustrates the concept of microgrid integration on the shore side and seaside.

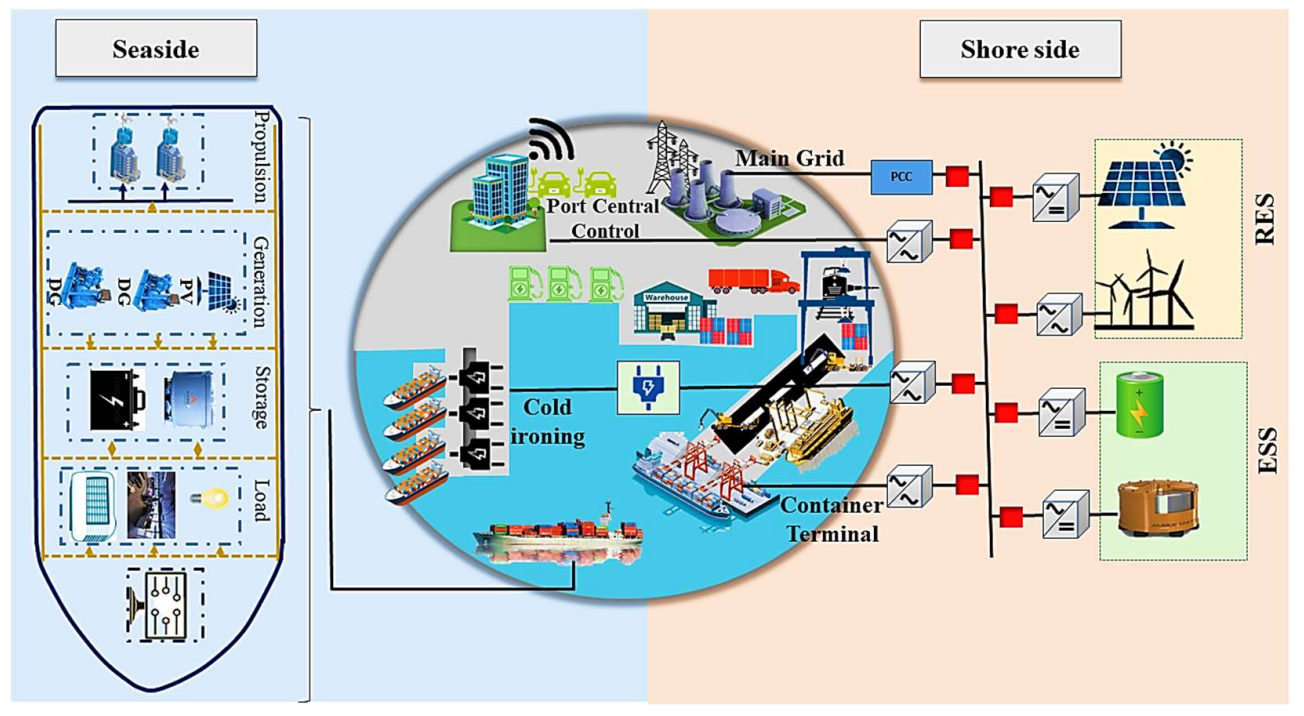

Figure 10. The concept of seaport microgrid on the shore and seaside.

German maritime sector is an example to manifest the integration of seaport microgrid, where Hamburg port draws a power of 24.5 MW from renewable energy by installing more than 20 units wind turbines [100]. Besides, their warehouse rooftops are filled with solar panels with projection to generate 500MWh of electricity per year [100]. German port emphasizes the importance of renewable energy as they are also considering other sources of energy like tidal power generation, wave energy, and geothermal energy [101]. Another positive step taken by Hamburg Port is towards electrification through the installation of cold ironing [50]. These measures are being developed to increase power supply while simultaneously assisting the port in achieving its green maritime goals.

On the shore side, microgrid integration will enhance more electrification and automation for port applications such as heavy lifting devices, transport machinery, and enables the transition from diesel to cold ironing during berthing [71]. Whereas, all of these practices are currently limited as the conventional grid cannot bear the heavy load.

By definition, a seaport microgrid refers to the port that employs microgrid technologies to support its power system and distributed loads. This incentive is to improve the port's operation efficiency, maximize renewable energy penetration, provide 
flexibility for storage installation and allow for more energy selling to the market through the main grid [62]. Basically, seaport microgrids share similarities with land-based microgrids but they have slight differences in some aspects.

Commonalities: The framework of seaport microgrid have the same components as land-based microgrids for instance, RES, ESS, converter, and load component. Both microgrids can operate in grid-connected and island modes. In this regard, their basic control and operation frameworks may be similar [62].

Differences: The significant difference between these two types of microgrids stems from their application. Land-based microgrids normally support the power necessary for building electrical appliances and the most common electric demand is for lighting, thermal, and HVAC systems [14]. Meanwhile, seaport microgrids must consider both the logistic and the electric side [62]. On the logistic side, a lot of factors need to be considered such as berth allocation [102], port crane scheduling [103], route and voyage scheduling [104], and various cargo transportation. On the electrical side, each application needs a different level of energy, and the energy is volatile depending on many factors.

In addition, cold ironing application on seaport microgrids will cause frequent berth in and berth out which will influence the microgrid performance. Even harder, the port is also restricted by the strict policy that is changing over time [104]. Many involved parties like port entities, port stakeholders, policy makers, port authorities, and government add difficulty in any decision in planning for the better ports. All of these circumstances make the seaport microgrids become more complex compared to the land-based microgrids. Further exploration on the system requirements and modifications for better seaport microgrids is necessary to have compatible and efficient ports.

\subsubsection{Seaside (Shipboard microgrid)}

Over the last century, ship power systems have evolved significantly. Previously, ships used to have separate generators for propulsion and service loads. S. Jayasinghe et al. [105] illustrated a single line diagram showing that two steam turbines with $32.2 \mathrm{MW}$ generators are used to supply the propulsion system while the service loads are powered by four steam turbines with 1.5 MW generators. In the 1880s, ships were equipped with electric power systems for the first time [60]. With the introduction of an integrated power system (IPS), a common set of generators could power both onboard load and electric propulsion. The invention of electric propulsion then resulted in the total electrification of shipboard power systems, referred to as AES. The innovation brings numerous advantages to the maritime ships by reducing manpower, minimize the maintenance workload, improve fuel consumption, fast start-up times and reduce emissions from diesel combustion [60].

AES is considered as the maritime microgrid because of the integration of microgrid technology on the shipboard power system. AES operates in both grid-connected and automation modes. It has similar components as a typical microgrid whereas generators and ESS deliver power via an energy network to supply the propulsion and ship's load. In future shipboard, renewable energy implementation like photovoltaic systems become trendy in the research study. However, the limited space in the ship makes it one big 
constraint. Energy management systems (EMS) in ships send the signal to the particular component through the communication network after determining the optimal and required outputs for generators and batteries [62]. Ships work in two modes of operation.

Berthed in mode: During berthing, AES is connected to the cold ironing system, receiving electricity so that its auxiliary engine can be turned off. This cold ironing normally gets the supply from the main grid. Hence, the same concept as the gridconnected mode of operation for land-based microgrids is applied.

Berthed out mode: In the situation where the ship becomes physically independent from the seaport, the electric connection between these two entities (port and ship) no longer exists. The AES voyage at sea is viewed as a mobile microgrid and in island mode of operation. It moves and supplies its entire onboard load with its power system.

\subsubsection{Operation management and energy planning of seaport microgrid}

The complexity of the coordination of various power resources in a microgrid, load management, synchronization with the main grid, meeting policy obligations and environmental criteria recognizes the importance of the power/energy management system (PMS/EMS) in the seaport microgrids. P. Xie et al. [106] categorized the PMS and EMS of shipboard power systems into rule-based and optimization-based techniques, where rule-based techniques are highly dependent on human expertise, preconfigured strategies, and priorities. Meanwhile, optimization-based techniques are becoming more trendy as they are capable to provide a better solution by using analytical strategies or numerical optimization algorithms [107]. The diverse assortment of the PMS/EMS strategies in a microgrid system entails managing each component and sub-component by hierarchical control schemes including primary, secondary, tertiary, and upper-level control systems [86]. It covers different technical areas, time scales, and physical levels.

In this section, the importance of the operation management system for better energy planning within the seaport microgrid is highlighted. The demand for energy in the maritime sector keeps increasing over time because of the expanding infrastructure, increasing size and number of seaport transportations, need for handling multi functions, and increase of the global demand for logistics. The load will continue to rise due to the above-mentioned factors, but there are several operational practices for controlling the energy demand, including load scheduling, load forecasting analysis, improving load factor, peak shaving, and enhancement of the ESS utilization. Besides, price and tax incentives also play a vital role in operation management of seaport microgrids.

\subsubsection{Load schedulling}

In maritime, seaport control on the shore side and seaside (shipboard power system) normally have different administrators that seek different goals [62]. The coordination between these two administrative bodies is necessary. For instance, the vessel could choose a berthed-in time when the electricity price is low, and the seaport can make more electricity price savings by adjusting the berth allocation during off-peak hours. Load scheduling at the time of the minimum electricity price is beneficial to the energy 
consumers to minimize the total electricity cost while at the same time meeting environmental requirements.

Pricing policy is one of the vital considerations in load scheduling as the price of electricity fluctuates over time. Different pricing policies apply to different applications in industries. Similarly, in the marine sector, to achieve energy-saving, and optimize the cost of energy, pricing policy plays a significant role. Sun and Li [108] describe two pricing policies, namely Time-Of-Use (TOU) pricing and Critical Peak Pricing (CPP). TOU pricing is a dynamic pricing strategy where electricity is charged at several price levels for offpeak, mid-peak, and on-peak intervals during the day [109]. This pricing strategy allows energy consumers to shift their loads from peak load intervals to off-peak periods and avoid high electricity prices [110]. In the peak event situation where the production is skyrocketing due to very high demand, CPP is the most effective scheme which selects one price for critical periods [111]. Kyaw Hein et al. [2] propose robust coordinated operational scheduling for grid-connected seaport microgrids. In that framework, shipto-shore (STS) power demand is scheduled by using day-ahead and hour-ahead scheduling with different time horizons. The aim is to reduce emissions and minimizing the cost of port operation.

In addition, this scheduling technique is widely used in shipboard microgrids. Unlike the land-based microgrids, AES at the sea operation can be regarded as mobile microgrids. Hence, power consumption is subject to the cruise speed and voyage distance. With the help of electric propulsion motors, AES is capable to adjust the cruising speed to achieve a more economical operation. AES operate at different speeds during different operating modes including docking mode (when ship approaching or leaving the port), cruising mode, and berthed mode. Yuqing Huang et al. [112] could reduce the operation cost and GHG emissions by $17.4 \%$ and $23.6 \%$ respectively by implementing voyage generation scheduling methods in the AES. In [113], the optimal scheduling for a ferry is achieved by employing a rule-based algorithm considering three scheduling models of different DG units and ESS. Simulation results show that by optimally scheduling the power sources on-board, poor low-load efficiency situation can be prevented. Appropriate DG selection and load scheduling for the ship can maximize fuel-saving. Srinivasa Rao K et al. [114] minimize the fuel consumption in an offshore support vessel with a dynamic positioning system by scheduling generation resources. The Genetic algorithm is applied for the optimal load sharing due to the nonlinear specific fuel consumption (FC) curves of diesel engines.

\subsubsection{Load factor improvement}

Load factor is expressed as the fraction of average load during a specified period to peak load in that timeframe [115]. This technique is useful to determine the efficiency of microgrid operation. A low load factor signifies that an electricity system is being operated inefficiently and economically poor [116]. Thus, a high load factor is desirable to ensure that the seaport microgrid is economically viable by utilizing the total plant capacity for the longest possible period [117]. As a result, the overall cost of providing electric energy will be reduced. F.Robert et al. [118] analyze the impact of different load 
factors of $0.2,0.3$, and 0.4 on the energy cost at the design stage of a microgrid. The analysis shows that the highest value of load factor can reduce the energy cost up to $48 \%$ approximately for a solar-based microgrid [118].

In the harbor, instead of running all the big operations such as heavy loading/unloading cargo and multiple ship berthing at the same time that cause peak demand in the specific time, scheduling time of ship and cargo arriving is a wise action. When all the high-demand operations are not running simultaneously, the peak demand can be distributed over the off-peak hours and increase the average load as well as the load factor.

At the same time, it will result in reducing the total energy purchase cost. Thus, improving the load factor by reducing or shifting the peak load is necessary to ensure the profitability of microgrid power systems [119]. In [113], power scheduling techniques are applied to a hybrid ferry microgrid. The results show that the right arrangement of DG and ESS is capable to improve the load factor.

\subsubsection{Peak shaving}

Electrification technologies in ports such as AES, transition from diesel-based cranes to electric cranes, cold ironing, electric vehicles, electric trains and electric trucks for cargo transportation change the port's dynamic behavior. Peak shaving is a favorable method to control the operational load at ports. Figure 11 illustrates three peak shaving techniques to scale down the peak load profile to low-demand time intervals.

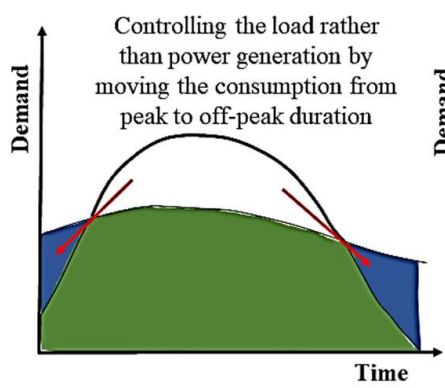

(a) Load Shifting

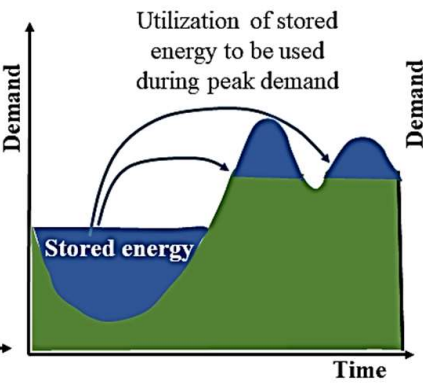

(b) Power Sharing

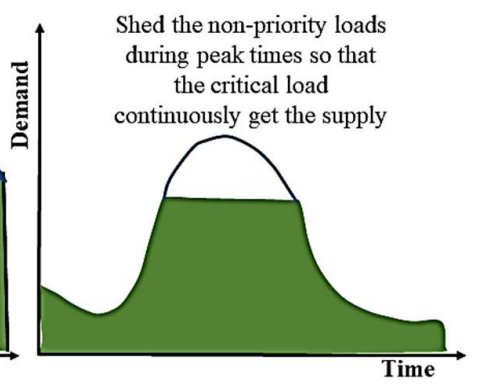

(c) Load Shedding

Figure 11. Peak shaving methods [24][26][120][121][67].

Peak shaving is based on the incorporation of energy storage systems. K. Mostafa et al. [26] coordinate the duty cycles for the STS cranes through full automation of the crane terminal and integrating peak shaving methods through deployment of ultra-capacitor (UC). The outcome shows that the higher amount of the peak load absorbed by the UC results in more operational earning. Harry Geerlings et al. [122] investigate the effectiveness of the peak shaving at container terminal (CT) by applying 'new rules of operation' with the aim of cost-saving while analyzing its effect on the handling time of containerships. They highlighted that peak shaving method not only reduces the handling cost at CT but also enhances the power stability. However, because the number of terminal equipment and processes operating at the same time may be limited, this may result in additional handling time for containerships [123]. This load leveling technique 
also applies to shipboard microgrids. In [91], to organize the operation in shipboard, a specialized hierarchical control scheme is proposed. Load sharing level in primary control aims to distribute the load from peak to off-peak hours. Peak shaving in the shipboard helps to absorb the load variation in the system so that engines can continue to operate at their most efficient operating point. Kiyoune Kwon et al. [92] proposed a load frequencybased approach to manage the shipboard power and load sharing in DC hybrid electric ships. Simulation results indicate that load frequency-based power management offers an effective load distribution and capable of protecting the generator from sudden load variations, which leads to poor power quality and causes damage in mechanical systems.

\subsubsection{Load forecasting}

In energy systems, load forecasting is a powerful tool for predicting load behavior using historical data to sustain energy at both supply and demand sides. Accurate load forecasting is significant for port operational planning and load management. Various techniques can be used to implement load forecasting ranging from parametric-based methods to the evolutional artificial intelligent techniques listed in Table 7. Different methods are exploited depending on the type of load forecasting, which can be classified into three major categories;

1) Short-term load forecast (STLF) - typically from one hour to one week for economic dispatch [124]

2) Medium-term load forecast (MTLF) - typically from one week to one year [125]

3) Long-term load forecast (LTLF)- typically longer than one year suitable for capacity expansion [125]

On the shore side, dynamic load from multiple operations of logistics (container terminal, cargo transportation, vessel, charging station) and administration infrastructure (communication center, warehouse building, and maintenance) might lead to unexpected power consumption peaks. Thus, large generation of power is required as energy shortage leads to the port operation disruption. Thus, load forecasting in port is vital to optimize resource utilization, schedule the load, and managing alternative energy from RES and ESS. 
Table 7. Load forecasting method [126][127][128].

\begin{tabular}{|c|c|c|}
\hline $\begin{array}{c}\text { Load } \\
\text { forecasting } \\
\text { approach }\end{array}$ & Technique & Parameter requirement \\
\hline $\begin{array}{l}\text { Traditional } \\
\text { parametric } \\
\text { techniques }\end{array}$ & $\begin{array}{l}\text { 1) Gray dynamic methods } \\
\text { 2) Regression methods } \\
\text { 3)Time-series prediction methods } \\
\text { (autoregressive (AR), moving average } \\
\text { (MA), autoregressive moving average } \\
\text { (ARMA), autoregressive integrated } \\
\text { moving average (ARIMA), Seasonal } \\
\text { Autoregressive Integrated Moving } \\
\text { Average (SARIMA), ARMAX) }\end{array}$ & \multirow{2}{*}{$\begin{array}{l}\text {-Historical data of load } \\
\text { profile } \\
\text { - Influential factors: } \\
\text { weather, air temperature, } \\
\text { humidity, wind speed, } \\
\text { calendar } \\
\text { information, economical } \\
\text { events, and geographical } \\
\text { information }\end{array}$} \\
\hline $\begin{array}{l}\text { Artificial } \\
\text { intelligence- } \\
\text { based } \\
\text { techniques } \\
\end{array}$ & $\begin{array}{l}\text { 1) Artificial neural network (ANN) } \\
\text { 2) Fuzzy logic } \\
\text { 3) Genetic algorithm (GA) } \\
\text { 4) Support Vector Machine (SVM) }\end{array}$ & \\
\hline
\end{tabular}

One of the electrification innovations in ports is related to the transition from a dieselpowered rubber-tyred gantry (RTG) to an electric RTG [129]. In order to understand the energy behavior of electric RTG, Feras Alasali et al. [130] implement three different method of load forecasting, namely ARIMAX, ANN, and ARMAX-SVN. The purpose is to find the most accurate forecasting method so that peak demand can be reduced effectively. Several simulation analyses are conducted implementing STLF techniques (24-hour) on the load profile of electric RTG crane from Port of Felixstowe[130]. Results show that ANN outperforms ARIMAX and ARIMAX-SVN forecasting technique.

Regarding the seaside microgrid (isolated shipboard), the dynamic positioning (DP) system, which is used in marine vessels to keep the ship position from displacement, is important to determine how thrusters should act to stabilize the position and heading of vessels. However, the uncertainty during the voyage that stems from sea waves and weather conditions affects the DP, vessel's speed as well as ship power. Hence, DP load forecasting by considering the uncertainty is essential for better shipboard power consumption management. M. Mehrzadi et al. [131] utilized deep learning method for DP load forecasting using Levenberg-Marquardt algorithm based on a nonlinear recurrent neural network to predict thruster's power consumption in different sea states. This practice greatly aids the ship's operation management and power system planning in order to maintain stability of the system, safety, robustness, and economic operation [131].

\subsubsection{Storage management}

The incorporation of a RES component in a seaport microgrid necessitates the use of an ESS to store the energy and discharge it during peak hours. Due to the weatherdependency of the RES power generation and uncontrolled weather conditions the energy from RES will fluctuate which highlights the importance of the ESS integration in microgrid power systems. Furthermore, it contributes to additional profit by selling excess energy back to the energy market via the utility grid. In marine vessels, ESS is beneficial for strengthening the system to avoid instability, which is caused by the engines' delay in 
responding to load demand [132]. It will also serve as an additional power reserve in the event of a generator failure, reducing the risk of a blackout. In [112],virtual ESS is used in AES for mutual support between voyage scheduling and economic dispatch. M. Othman et al. [113] utilize ESS for power generation scheduling in a hybrid shipboard microgrid.

M. Mutarraf et al. [20] signify the importance of the battery banks in DC bus seaport microgrid to provide a mobile cold ironing facility at the harbor. Due to the high dynamic behavior of the port's load, ESS management and wise distribution of RES and ESS during peak and off-peak duration help greatly in balancing the demand and supply. For instance, in a case that a sudden high-energy demand from cold ironing due to the arrival of multiple big vessels at the same time is required and the power generation from RES is not enough to cover the entire demand, the ESS can come to scene. Baizura et al. [16] model a flywheel energy storage system to harvest energy from the harbor electrical cranes. Besides, ESS can also help for improving the robustness of seaport microgrids under uncertainty [2].

A number of different methods for reducing peak demand have been proposed in the literature. Some countries offer rewarding incentives so that energy consumers willingly shift their electricity consumption to off-peak periods. An ESS has merit over this rewarding program in allowing customers to have their normal daily lives while lowering their peak demand charge. The cost-benefit analysis is based on the battery's lifespan, state of health, and discharge time [116]. With the increase in storage capacity, more loads can be scheduled at the minimum cost duration, thereby reducing the potential for higher electricity charges [133]. The trade-off between financial gain and operational efficiencies is quantified.

\subsubsection{Price and tax incentive}

Demand response is an efficient strategy to moderate electricity consumption in response to the market incentives either price or tax reduction. There are two types of demand response programs: time-based rate (TBR) programs and incentive-based programs (IBPs) [134]. TBR programs provide consumers with time-varying rates based on the price of electricity in different periods (real-time pricing (RTP), TOU, and CPP), motivating users to adjust their consumption patterns through changing price signals [135]. On the other hand, IBP is the form of incentive that gives the advantage in the time of stress. Considering environmental issues at the port, port authorities from U.S and E.U offer shipping rebates to reward ship operators that satisfy environmental requirements [136]. In practice, the Port of Long Beach implemented the Green Ship incentive program to reduce NOx emissions from shipping [31]. Another alternative is the introduction of various environmental indexes such as the Environmental Ship Index (ESI), Green Award (GA), the Clean Shipping Index (CSI), and Blue Angel (BA)[31]. These programs give special discounts on port dues if the port score satisfies the baseline index. For instance, in Bremen, ships with an ESI score of 30 to 40 receive a $5 \%$ discount on port dues, while ships with an ESI score of more than 40 receive a $10 \%$ discount. These incentives will encourage the port entities to take the necessary actions to improve their port so that they 
can achieve more discounts on port dues. J. Sanz et al. [137] review four types of incentives for microgrid which are; 1) feed in tariffs, 2) market premium, 3) green certificates, and 4) tenders. Each incentive is initiated for different conditions and rewards but with the same goal toward energy saving and zero foot print ports.

\section{Seaport microgrid challenges and future trends}

\subsection{Challenges in developing microgrid system at seaports}

The increasing number of publications from researchers around the world indicates a growing trend towards maritime microgrids. However, real implementation of seaport microgrids in the harbor is scarce due to several issues and barriers that exist from various perspectives. Anthony Roy et al. [54] discuss a few aspects of seaport microgrids, namely technical and managerial. Security and regulatory aspects are also among the important perspective. Some of these challenges are addressed below.

\subsubsection{Technical challenge}

Relying solely on the utility grid is inefficient considering heavy appliances at the harbor. The grid must be close to the port, or the cables will be very expensive. Thus, harnessing energy from RES is more economical due to the local generation advantages. However, ports have a limited space for RES installation [96]. Undeniably, solar panels can be installed on the flat rooftop of the buildings or warehouse but with restricted capacity and it is not applicable for large-scale exploitation. Shipboard microgrids suffer from the same problem. Many of the commercial AES use diesel generators and batteries for propulsion and supplying onboard loads [138].

For the next AES evolution, implementation of RES such as photovoltaic systems is discussed in [62] to support the power required by the shipboard microgrid. However, there is no discussion on a compatible unit of solar panels that can be placed on the ship. It is well known that ships have very limited space due to existing bulky equipment on board, especially cargo ships, which usually use the space to place the cargo. Furthermore, coordination of the RES will be complicated because ships are always on the move and isolated when they are at sea [96].

For the wind turbines, installation can take up a significant portion of land and deforestation to set up a wind farm treats the wildlife such as birds and bats. Besides, it does not only require high upfront investment but is also prone to noise disturbance and bad visual impact.

Another challenge for RES installation is the uncertainty in weather conditions. RES are unable to produce a consistent power and their power production depends on several factors such as ambient temperature, wind speed, irradiation, and time of the season, among others. Hence, storage elements are always integrated with the RES.

\subsubsection{Managerial}

According to the literature, a few ports, such as Port of Hamburg and Port of Genoa, have already taken the initiative for microgrid deployment [139]. In comparison to the massive use of land-based microgrids, port-based microgrid implementation is considered scarce. This situation creates an opportunity to bring microgrids technology into seaports, but it is also difficult to access references in terms of their needs, design, operation, and maintenance requirements. Especially during the design phase, it is a complicated task to find the optimal design of the seaport microgrid with the compatible configuration and the right size of its components. The research conducted on testing and analysis of seaport microgrids is lacking real-life data. This can be explained by many of the studies 
that are conducted based on the simulated data sets. Thus, it is hard to know if the simulation result is compatible with the real implementation or not.

In addition, considering that the seaport microgrid is a relatively new topic, the manpower that has the expertise and enough experience is limited. Because of this, port entities find that the new power system technology is difficult to handle, leading them to decide not to take any risks by denying microgrid implementation. Not only that, the planning for the implementation takes a long time before it can be executed. Revolutionizing the ports to the microgrid technology may look great on paper. However, one of the biggest hurdles to overcome is the human factor with different mentalities. Besides, the requirement to make an agreement and synchronization between all parties involved such as port entities, stakeholders, port authorities, policymakers, and government makes it more difficult. That explains the reason why the majority of the ports are comfortable with the traditional power system.

\subsubsection{Security and regulation}

Operation management and control of seaport microgrids are very different from conventional power systems due to the characteristics of power electronic converters and high dynamic load behavior. Port is the site that has highly volatile loads due to the frequent arrival and departure of ships. Microgrids must achieve a balance between supply and demand to maintain voltage/frequency stability. Especially during isolated operations, system instability is a major concern. To effectively manage these issues, hierarchical control techniques have been proposed [24]. On top of this, shore-side and shipboard microgrids (seaside) have different administration and rules of conduct.

In terms of security, the lack of an efficient monitoring system makes microgrids extremely vulnerable to cyber threats [140]. Malicious cyber assaults are a threat to power network operations, causing massive damages from different technical, economic, social, and control points of view. According to statistics from the energy sector, more than 150 cyber-attacks occurred in 2013 and 79 in 2014 [141]. Accordingly, the cost of power outages in the United States is estimated to be around $\$ 80$ billion per year [141].

Above all of the aforementioned concerns, one of the biggest challenges of the maritime sector is the implementation of strict policies for marine operations both on the shore and seaside. Either to restrict emissions or to stimulate the use of improved technologies at ports, policy regulations are in place. These guidelines must be followed in any future port planning. It is becoming more difficult for existing appliances that require immediate replacement. In accordance with a current IMO rule limiting sulfur content in fuel to 0.5 $\% \mathrm{~m} / \mathrm{m}$, ships must either find alternative clean fuels or integrate a fully electric ship.

On the positive side, certain legislation exists that provides incentives and subsidies to stimulate the use of new technologies. Taxes, for example, are proposed as a strategy by increasing tax on older systems while lowering taxes on newer systems. It is important to formulate legislation scheme that favors microgrids as a power system at port, as this legislation framework will result in switching to microgrids that are more cost-effective than staying with conventional fossil-fuel-based systems. Adam Hirsch et al.[110] attracted the attention to two key questions about the rules that require clarification, where the answer eventually has a significant influence on microgrids. The first question is whether microgrid is considered as electrical distribution utilities and thus subject to state regulatory control or not. The second clarification is, in the case that microgrids are excluded from state regulation as utilities, do microgrids fit into existing legal frameworks governing energy sale and purchase, as well as rights to generate and distribute electricity. Microgrids require a rightful legal identity and regulatory certainty to ensure their implementation is profitable. Or else, the upfront cost is too high and the profit is too uncertain to rationalize with the investment of time and money.

\subsection{Potential future research directions}


The ongoing challenges of seaport microgrids including the barriers mentioned in the above subsection and other technical aspects require more investigation to find effective solutions to improve the ports' performance. The know-how to manage all of these will benefit the ports in a variety of ways, including energy efficiency, cost-saving, and environmental issues. Below are some of the identified potential issues on the seaport microgrids that can be considered for future studies;

\subsubsection{Mobile cold ironing}

Currently, cold ironing in the harbors mostly uses direct energy from the main grid. There is a chance that a few large vessels with high power requirements will arrive at the same time. Thereby, the reliance on grid supply alone is insufficient to keep all parts of ports operational and might result in power shortages. Furthermore, most of the smaller seaports are not equipped with cold ironing stations resulting in continuous pollution from auxiliary engines during berthing [20]. To address these issues, mobile cold ironing by forming a power-sharing network between nearby ships called a 'moveable shipboard microgrid' appears to be a potential solution for providing temporary power. Further research on this technique can be pursued to put it into practice.

\subsubsection{Optimal port planning}

Considering that seaport microgrids involve different kinds of load, various objectives, and constraints, it is critical to plan efficient coordination among the components in the microgrid. There is limited literature that addresses the compatible configuration and appropriate size/capacity for each component in a seaport microgrid. Outstanding coordination is needed besides determining the right type of RES/storage component/converter installation and suitable topology. This is to ensure that there is no lacking or oversizing in microgrid implementation, allowing power to be distributed efficiently and avoiding unnecessary investments.

\subsubsection{Cluster seaport microgrid}

From the available literature, most of the publications on seaport microgrids contribute to the overall performance of the microgrid. However, the port itself deals with many kinds of large energy applications such as container terminals, cold ironing, cargo transportation, vessel, and administrative buildings for port handling. Thus, it is a good opportunity to implement a cluster seaport microgrid by grouping the loads into different load clusters.

\subsubsection{Optimization}

Due to the current firm policy for the port operation to control prolonged toxic pollution, an optimization algorithm that will benefit both the legislative body and the port entity is required. The analysis will help port entities in future planning so that it is compatible with the port policy.

\subsubsection{Economical analysis}

All the alternatives carry out in the marine sector from renewable energy harnessing to electrification innovation undeniably bring a plentiful amount of energy-saving and emission reduction benefits. Most of the previous researches has focused on the technical aspects and a comprehensive economic analysis is still lacking. For a stakeholder, financial management and revenue generation from investment is vital before executing any planning process. Further economic analysis on the seaport considering the market price, the tax charged, energy price, and return on investment would be necessary. Another alternative for future study is to create an economic model that benefits all parties in the port. 


\section{Conclusions}

Ports are sites with major contributions to pollution as large vessels keep their engines running even when berthed and heavy lifting work is operated by diesel-powered cranes. Dynamic behavior and the diversity of the port applications emphasize the promising role of microgrid technology in supporting the utility grid. This paper addressed the concept of the seaport microgrid and its integration into seaport from both shore and seaside (shipboard microgrid) points of view as well as its operational management. After the thorough literature review, the following are some of the significant conclusions drawn in this paper:

- Three major concerns at the ports are energy, environment, and cost. Future port planning should be geared toward addressing these issues.

- A microgrid is a promising power system for the marine sector, capable of supporting the industry's heavy loads. It enables the diversification of alternative energy resources, such as harnessing from RES, rather than being limited to only fossil-based energy. Port will manage to achieve a substantial amount of cost-saving since the electricity is generated locally by RES in the harbor area. It will reduce the investment cost in both utility grid expansion and long distribution cables.

- Furthermore, the ESS components in the microgrids help in improving port performance and serve as a useful tool for demand-side management. The good practice from the operation management in seaport microgrids enhances better operation at a lower price.

- With a seaport microgrid, it is possible to bring more electrification and automation into the ports that the conventional grid cannot support such as supporting large-scale cold ironing, full electrification of cranes, improved charging stations, and electrification of other modes of transportation.

Electrification movement in the ports implies that the connections between seaport and ships are no longer on the logistic side only but also on the electric side. It requires an efficient transportation system and power system, makes the seaport microgrid more complicated than the traditional land-based microgrids. Thus, further actions for improvement in ports is needed to synchronize both logistic and energy side in a more coordinated way.

Author Contributions: Conceptualization, N.N.A.B; software, N.N.A.B and Y.Y; validation, N.B.; formal analysis, N.N.A.B., visualization, N.N.A.B and Y.Y, writing-original draft preparation, N.N.A.B.; writing - review and editing, N.N.A.B and N.B.; supervision, J.M.G. and J.V.; project administration, J.M.G.; funding acquisition, J.M.G. All authors have read and agreed to the published version of the manuscript.

Funding: This research was funded by a Villum Investigator from The Villum Fonden, grant number 25920 .

Data Availability Statement: Not applicable.

Acknowledgments: This research work was supported by a Villum Investigator grant (no. 25920) from The Villum Fonden, University Malaysia Perlis, and Ministry of Education Malaysia. The Deanship of Scientific Research (DSR) at King Abdulaziz University, Jeddah, Saudi Arabia has funded this project, under grant no. (RG-22-135-41).

Conflicts of Interest: The authors declare no conflict of interest.

\section{References}

[1] K. Hein, Y. Xu, W. Gary, and A. K. Gupta, "Robustly coordinated operational scheduling of a grid-connected seaport microgrid under uncertainties," no. September, pp. 1-12, 2020, doi: 10.1049/gtd2.12025. 
[2] K. Hein, Y. Xu, W. Gary, and A. K. Gupta, "Robustly coordinated operational scheduling of a grid-connected seaport microgrid under uncertainties," IET Gener. Transm. Distrib., vol. 15, no. 2, pp. 347-358, 2021, doi: 10.1049/gtd2.12025.

[3] "No Title," Royal Caribbean International, 2021. https://www.royalcaribbean.com/cruise-ships/symphony-of-the-seas.

[4] M. M. Kidere, "Analytical assessment of port energy efficiency and management .: a case study of the Kenya Ports Authority," 2017.

[5] A. Hlali and S. Hammami, "Seaport Concept and Services Characteristics: Theoretical Test," Open Transp. J., vol. 11, no. 1, pp. 120-129, 2018, doi: 10.2174/1874447801711010120.

[6] A. Molavi, G. J. Lim, and B. Race, "A framework for building a smart port and smart port index," Int. J. Sustain. Transp., vol. 0, no. 0, pp. 1-13, 2019, doi: 10.1080/15568318.2019.1610919.

[7] A. Kaliszewski, "Fifth and Sixth Generation Ports ( 5Gp ,6Gp ) - Evolution of Economic and Social Roles," ResearchGate, no. April, p. 32, 2018, [Online]. Available: https://www.researchgate.net/publication/324497972\%0AFIFTH.

[8] A. Montwiłł, "The Role of Seaports as Logistics Centers in the Modelling of the Sustainable System for Distribution of Goods in Urban Areas," Procedia - Soc. Behav. Sci., vol. 151, pp. 257-265, 2014, doi: 10.1016/j.sbspro.2014.10.024.

[9] P. W. de Langen, "Governance in Seaport Clusters," Palgrave Macmillan, London.

[10] N. B. Bintiahamad, "Integration of Microgrid Technologies in Future Seaports," 2019, [Online]. Available: https://www.forskningsdatabasen.dk/en/catalog/2471559831.

[11] G. Versteegt, “Berthing Loads in Strcutural Design,” 2013.

[12] P. W. De Langen and K. Sharypova, "Intermodal connectivity as a port performance indicator," Res. Transp. Bus. Manag., vol. 8, pp. 97-102, 2013, doi: 10.1016/j.rtbm.2013.06.003.

[13] N. Sifakis and T. Tsoutsos, “Planning zero-emissions ports through the nearly zero energy port concept," J. Clean. Prod., vol. 286, p. 125448, 2021, doi: 10.1016/j.jclepro.2020.125448.

[14] N. N. Abu Bakar et al., "Energy efficiency index as an indicator for measuring building energy performance: A review," Renew. Sustain. Energy Rev., vol. 44, pp. 1-11, 2015, doi: 10.1016/j.rser.2014.12.018.

[15] H. X. Zhao and F. Magoulès, “A review on the prediction of building energy consumption," Renew. Sustain. Energy Rev., vol. 16, no. 6, pp. 3586-3592, 2012, doi: 10.1016/j.rser.2012.02.049.

[16] N. B. binti Ahamad, C. L. Su, X. Zhaoxia, J. C. Vasquez, and J. M. Guerrero, “Modeling and controls of flywheel energy storage systems for energy harvesting from harbor electrical cranes," 2018 IEEE Ind. Appl. Soc. Annu. Meet. IAS 2018, pp. 18, 2018, doi: 10.1109/IAS.2018.8544652.

[17] B. Comer, N. Olmer, X. Mao, B. Roy, and D. Rutherford, “Prevalence of heavy fuel oil and black carbon in Arctic shipping, 2015 to 2025," Int. Counc. Clean Transp., no. May, p. 68 pp, 2017, [Online]. Available: https://www.theicct.org/publications/prevalence-heavy-fuel-oil-and-black-carbon-arctic-shipping-2015-2025.

[18] K. Yiğit, G. Kökkülünk, A. Parlak, and A. Karakaş, “Energy cost assessment of shoreside power supply considering the smart grid concept: a case study for a bulk carrier ship," Marit. Policy Manag., vol. 43, no. 4, pp. 469-482, 2016, doi: 10.1080/03088839.2015.1129674.

[19] J. S. Thongam, M. Tarbouchi, A. F. Okou, D. Bouchard, and R. Beguenane, "All-electric ships - A review of the present state of the art," 2013 8th Int. Conf. Exhib. Ecol. Veh. Renew. Energies, EVER 2013, pp. 1-8, 2013, doi: 10.1109/EVER.2013.6521626.

[20] M. U. Mutarraf et al., "A Decentralized Control Scheme for Adaptive Power-Sharing in Ships based Seaport Microgrid.," IECON Proc. (Industrial Electron. Conf., vol. 2020-Octob, pp. 3126-3131, 2020, doi: 10.1109/IECON43393.2020.9255344.

[21] N. B. B. Ahamad, J. M. Guerrero, C. L. Su, J. C. Vasquez, and X. Zhaoxia, “Microgrids Technologies in Future Seaports,” Proc. - 2018 IEEE Int. Conf. Environ. Electr. Eng. 2018 IEEE Ind. Commer. Power Syst. Eur. EEEIC/I CPS Eur. 2018, pp. 1-6, 2018, doi: 10.1109/EEEIC.2018.8494428.

[22] L. T. W. N. Kusuma and F. S. Tseng, “Analysis of the impact of the 'sea toll' program for seaports: Resilience and competitiveness," Appl. Sci., vol. 9, no. 16, 2019, doi: 10.3390/app9163407. 
[23] M. Boile, S. Theofanis, E. Sdoukopoulos, and N. Plytas, “Developing a port energy management plan: Issues, challenges, and prospects," Transp. Res. Rec., vol. 2549, no. 2549, pp. 19-28, 2016, doi: 10.3141/2549-03.

[24] M. Sadiq et al., "Future Greener Seaports: A Review of New Infrastructure, Challenges, and Energy Efficiency Measures," IEEE Access, vol. 9, pp. 75568-75587, 2021, doi: 10.1109/access.2021.3081430.

[25] "Port Of Wilmington Cold Storage becomes first in-port cold storage facility in North Carolina." https://www.provisioneronline.com/articles/104257-port-of-wilmington-cold-storage-becomes-first-in-port-cold-storagefacility-in-north-carolina.

[26] K. Mostafa, P. Giuseppe, C. Ben, and M. Luigi, “Ultracapacitors for Port Crane Applications : Sizing and Techno-Economic Analysis," Energies, vol. 13, 2020.

[27] M. Kermani, G. Parise, L. Martirano, L. Parise, and B. Chavdarian, “Optimization of Peak Load Shaving in STS Group Cranes Based on PSO Algorithm," Proc. - 2018 IEEE Int. Conf. Environ. Electr. Eng. 2018 IEEE Ind. Commer. Power Syst. Eur. EEEIC/I CPS Eur. 2018, 2018, doi: 10.1109/EEEIC.2018.8494467.

[28] R. Hariharan, P. Usha Rani, and P. Muthu Kannan, "Sustain the Critical Load in Blackout Using Virtual Instrumentation," in Intelligent and Efficient Electrical Systems, 2018, pp. 77-88.

[29] R. Pei, J. Xie, H. Zhang, K. Sun, and Z. Wu, “Robust Multi-Layer Energy Management and Control Methodologies for Reefer Container Park in Port Terminal," 2021.

[30] M. P. Rosa Mari Darbra, Chris Wooldridge, “ESPO Environmental Report 2020," 2020. [Online]. Available: https://www.espo.be/media/Environmental Report-WEB-FINAL.pdf.

[31] X. Zhang, "Analysis of the incentives in environmental strategies implementation in Chinese ports by," pp. 1-76, 2016.

[32] Ø. Endresen et al., "Emission from international sea transportation and environmental impact," J. Geophys. Res. Atmos., vol. 108, no. 17, 2003, doi: 10.1029/2002jd002898.

[33] S. L. Chen, "Port administrative structure change worldwide: Its implication for restructuring port authorities in Taiwan," Transp. Rev., vol. 29, no. 2, pp. 163-181, 2009, doi: 10.1080/01441640802260248.

[34] M. Dooms, L. Van der Lugt, and P. W. De Langen, "International strategies of port authorities: The case of the Port of Rotterdam Authority," Res. Transp. Bus. Manag., vol. 8, no. May 2018, pp. 148-157, 2013, doi: 10.1016/j.rtbm.2013.06.004.

[35] OECD, “Towards Green Growth,” 2011. https://www.oecd.org/education/skills-beyond-school/48631582.pdf.

[36] I. M. O. (IMO), “IMO $2020 \quad-\quad$ cutting sulphur oxide emissions." https://www.imo.org/en/MediaCentre/HotTopics/Pages/Sulphur-2020.aspx.

[37] J. K. Woo, D. S. H. Moon, and J. S. L. Lam, “The impact of environmental policy on ports and the associated economic opportunities," Transp. Res. Part A Policy Pract., vol. 110, no. September, pp. 234-242, 2018, doi: 10.1016/j.tra.2017.09.001.

[38] M. Acciaro, H. Ghiara, M. Inés, and M. I. Cusano, “Energy management in seaports: A new role for port authorities,” Energy Policy, vol. 71, pp. 4-12, 2014, doi: 10.1016/j.enpol.2014.04.013.

[39] M. E. Portal, “greenport," 2021. https://www.greenport.com/news101/Projects-and-Initiatives/shipowners-to-reap-moregreen-rewards.

[40] S. Roh, V. V. Thai, and Y. D. Wong, “Towards Sustainable ASEAN Port Development: Challenges and Opportunities for Vietnamese Ports," Asian J. Shipp. Logist., vol. 32, no. 2, pp. 107-118, 2016, doi: 10.1016/j.ajsl.2016.05.004.

[41] F. M. Edoho, "Oil transnational corporations: corporate social responsibility and environmental sustainability," Corp. Soc. Responsib. Environ. Manag., vol. 15, pp. 210-222, 2008.

[42] S. Z. Matishov GG, “New scientifically based methods for controlling ship ballast in ports," vol. 422:342-4, doi: 10.1134/s0012496608050190.

[43] B. Behrends, P. G. Liebezeit, and D. Gregory, "Reducing SO 2 and NO X emissions from Ships by a seawater scrubber," no. X, 2003.

[44] R. Fouquet, “Energy Research \& Social Science Historical energy transitions : Speed , prices and system transformation ๕,,” 
Chem. Phys. Lett., vol. 22, pp. 7-12, 2016, doi: 10.1016/j.erss.2016.08.014.

[45] “The Purchase of the British Government' s Shares in the British Petroleum Company Author ( s ): Marian Jack Source : Past \& Present , Apr ., 1968 , No . 39 ( Apr ., 1968 ), pp . 139-168 Published by : Oxford University Press on behalf of The Past and Pre," vol. 39, no. 39, pp. 139-168, 1968.

[46] L. W. Davis and L. Kilian, “ESTIMATING THE EFFECT OF A GASOLINE TAX,” vol. 1214, no. February 2010, pp. 1187-1214, 2011, doi: 10.1002/jae.

[47] E. Furuholt, “Life cycle assessment of gasoline and diesel,” vol. 3449, no. November 1992, pp. 251-263, 1995.

[48] “Heavy Fuel Oil," 2015. https://www.oiltanking.com/en/news-info/glossary/details/term/heavy-fuel-oil-hfo.html.

[49] T. G. Papoutsoglou, “A Cold Ironing Study o Modern Ports, Implementation and Benefits Thriving for Worldwide Ports," 2012.

[50] A. Innes and J. Monios, "Identifying the unique challenges of installing cold ironing at small and medium ports - The case of aberdeen," Transp. Res. Part D Transp. Environ., vol. 62, no. March, pp. 298-313, 2018, doi: 10.1016/j.trd.2018.02.004.

[51] M. U. Mutarraf et al., “A Communication-less Multi-mode Control Approach for Adaptive Power-Sharing in Ships-based Seaport Microgrid," IEEE Trans. Transp. Electrif., vol. 7782, no. c, pp. 1-1, 2021, doi: 10.1109/tte.2021.3087722.

[52] S. Mocci, M. Porru, A. Serpi, and G. G. Soma, “The POSEIDON Project: Microgrid in Port Areas to Improve Energy Efficiency by the Integration of RES, Flexible Loads and Smart Mobility," Synerg. MED 2019 - 1st Int. Conf. Energy Transit. Mediterr. Area, pp. 1-5, 2019, doi: 10.1109/SyNERGY-MED.2019.8764116.

[53] N. A. S. Salleh, W. M. W. Muda, and S. S. Abdullah, “Feasibility study of optimization and economic analysis for gridconnected renewable energy electric boat charging station in Kuala Terengganu," 2015 IEEE Conf. Energy Conversion, CENCON 2015, pp. 510-515, 2015, doi: 10.1109/CENCON.2015.7409597.

[54] A. Roy, F. Auger, J. Olivier, E. Schae, and B. Auvity, “Microgrids in Harbor Areas : A Review,” pp. 1-24, 2020.

[55] A. SOH, “Jurong Port starts world's largest port-based solar facility," 2016. https://www.businesstimes.com.sg/energycommodities/jurong-port-starts-worlds-largest-port-based-solar-facility.

[56] "No Title," [Online]. Available: https://safety4sea.com/port-of-aalborg-becomes-the-first-co2-neutral-port-in-denmark/.

[57] M. Shahidehpour and J. F. Clair, "A Functional Microgrid for Enhancing Reliability, Sustainability, and Energy Efficiency," Electr. J., 2012, doi: 10.1016/j.tej.2012.09.015.

[58] J. M. Vleugel and F. Bal, “Cleaner air in seaport container terminals: Assessing fuel(s)," WIT Trans. Ecol. Environ., vol. 181, pp. 25-36, 2014, doi: 10.2495/EID140031.

[59] A. V. D. B. G. G. e. Al., “The role of voltage controls in modern all electrical ships toward the all-electric ship," IEEE Electrif. Mag., vol. vol 3, no. no 2, pp. 49-65, 2015.

[60] T. J. McCoy, “Electric Ships Past, Present, and Future [Technology Leaders],” IEEE Electrif. Mag., vol. 3, no. 2, pp. 4-11, 2015, doi: 10.1109/MELE.2015.2414291.

[61] and J. F. H. M. Murphy, J. May, R. Riksheim, “International Cooperation On Marine Engineering Systems / Electric Propulsion - State-of-the-art and Trends in Electric Power Generation, Distribution, and Propulsion , and their Associated Control Systems Report from Technical Committee B : Electric pr," pp. 1-36, 2000.

[62] S. Fang, Y. Wang, B. Gou, and Y. Xu, “Toward Future Green Maritime Transportation: An Overview of Seaport Microgrids and All-Electric Ships," IEEE Trans. Veh. Technol., vol. 69, no. 1, pp. 207-219, 2020, doi: 10.1109/TVT.2019.2950538.

[63] A. Durakovic, "First Turbine in at Denmark's Largest Offshore Wind Farm." https://www.offshorewind.biz/2021/01/27/firstturbine-in-at-denmarks-largest-offshore-wind-farm/.

[64] A. Durakovic, “Denmark's Largest Offshore Wind Farm Stands Complete." https://www.offshorewind.biz/2021/06/07/denmarks-largest-offshore-wind-farm-stands-complete/.

[65] "Kriegers Flak project demonstrates rapidly falling costs for offshore wind," WindEurope. https://windeurope.org/newsroom/news/kriegers-flak-project-demonstrates-rapidly-falling-costs-for-offshore-wind/. 
[66] X. Ding and Z. Yang, "Knowledge mapping of platform research: a visual analysis using VOSviewer and CiteSpace," Electron. Commer. Res., no. 0123456789, 2020, doi: 10.1007/s10660-020-09410-7.

[67] N. N. A. Bakar, M. Y. Hassan, M. F. Sulaima, M. N. im Mohd Nasir, and A. Khamis, "Microgrid and load shedding scheme during islanded mode: A review," Renew. Sustain. Energy Rev., vol. 71, no. November 2016, pp. 161-169, 2017, doi: 10.1016/j.rser.2016.12.049.

[68] K. S. Rajesh, S. S. Dash, R. Rajagopal, and R. Sridhar, “A review on control of ac microgrid," Renewable and Sustainable Energy Reviews. 2017, doi: 10.1016/j.rser.2016.12.106.

[69] S. Y. M. Mousavi, A. Jalilian, M. Savaghebi, and J. M. Guerrero, "Flexible compensation of voltage and current unbalance and harmonics in microgrids," Energies, vol. 10, no. 10, pp. 1-19, 2017, doi: 10.3390/en10101568.

[70] O. Farrok, M. R. I. Sheikh, and M. R. Islam, “An advanced controller to improve the power quality of microgrid connected converter," ICEEE 2015 - 1st Int. Conf. Electr. Electron. Eng., no. November, pp. 185-188, 2016, doi: 10.1109/CEEE.2015.7428251.

[71] British Columbia Ministry of Agriculture, "Market Opportunity Report: JAPAN," no. December, 2014, doi: 10.13140/RG.2.2.28781.61922.

[72] Z. Huang, T. Zhu, Y. Gu, D. Irwin, A. Mishra, and P. Shenoy, "Minimizing electricity costs by sharing energy in sustainable microgrids," BuildSys 2014 - Proc. 1st ACM Conf. Embed. Syst. Energy-Efficient Build., pp. 120-129, 2014, doi: $10.1145 / 2676061.2674063$.

[73] A. M. A. Haidar, A. Fakhar, and A. Helwig, "Sustainable energy planning for cost minimization of autonomous hybrid microgrid using combined multi-objective optimization algorithm," Sustain. Cities Soc., vol. 62, no. December 2019, p. 102391, 2020, doi: 10.1016/j.scs.2020.102391.

[74] H. Lotfi and A. Khodaei, “AC versus DC microgrid planning,” IEEE Trans. Smart Grid, vol. 8, no. 1, pp. 296-304, 2017, doi: 10.1109/TSG.2015.2457910.

[75] X. Lu, M. B. McElroy, C. P. Nielsen, X. Chen, and J. Huang, “Optimal integration of offshore wind power for a steadier, environmentally friendlier, supply of electricity in China," Energy Policy, vol. 62, pp. 131-138, 2013, doi: 10.1016/j.enpol.2013.05.106.

[76] X. Wu, Z. Wang, T. Ding, and Z. Li, “Hybrid AC/DC microgrid planning with optimal placement of DC feeders,” Energies, vol. 12, no. 9, pp. 1-23, 2019, doi: 10.3390/en12091751.

[77] J. J. Justo, F. Mwasilu, J. Lee, and J. W. Jung, “AC-microgrids versus DC-microgrids with distributed energy resources: A review," Renew. Sustain. Energy Rev., vol. 24, no. August, pp. 387-405, 2013, doi: 10.1016/j.rser.2013.03.067.

[78] L. Gao, Y. Liu, H. Ren, and J. M. Guerrero, “A DC microgrid coordinated control strategy based on integrator current-sharing," Energies, vol. 10, no. 8, 2017, doi: 10.3390/en10081116.

[79] J. Lago and M. L. Heldwein, “Operation and control-oriented modeling of a power converter for current balancing and stability improvement of DC active distribution networks," IEEE Trans. Power Electron., vol. 26, no. 3, pp. 877-885, 2011, doi: 10.1109/TPEL.2011.2105284.

[80] H. Kakigano, Y. Miura, T. Ise, and R. Uchida, “DC micro-grid for super high quality distribution - system configuration and control of distributed generations and energy storage devices," PESC Rec. - IEEE Annu. Power Electron. Spec. Conf., 2006, doi: 10.1109/PESC.2006.1712250.

[81] Z. Jin, M. Savaghebi, J. C. Vasquez, L. Meng, and J. M. Guerrero, "Maritime DC microgrids - A combination of microgrid technologies and maritime onboard power system for future ships," 2016 IEEE 8th Int. Power Electron. Motion Control Conf. IPEMC-ECCE Asia 2016, pp. 179-184, 2016, doi: 10.1109/IPEMC.2016.7512282.

[82] R. Prenc, A. Cuculić, and I. Baumgartner, “Advantages of using a DC power system on board ship," J. Marit. Transp. Sci., vol. 52, no. 1, pp. 83-97, 2016, doi: 10.18048/2016.52.05.

[83] D. Fregosi et al., "A comparative study of DC and AC microgrids in commercial buildings across different climates and operating profiles," 2015 IEEE 1st Int. Conf. Direct Curr. Microgrids, ICDCM 2015, no. April, pp. 159-164, 2015, doi: 


\subsection{9/ICDCM.2015.7152031.}

[84] X. Liu, P. Wang, and P. C. Loh, “A Hybrid AC / DC Microgrid and Its,” vol. 2, no. 2, pp. 278-286, 2011.

[85] J. M. Guerrero et al., “Shipboard microgrids: maritime islanded power systems technologies," PCIM Asia 2016 - Int. Exhib. Conf. Power Electron. Intell. Motion, Renew. Energy Energy Manag., no. June, pp. 28-30, 2016.

[86] M. D. A. Al-Falahi, T. Tarasiuk, S. G. Jayasinghe, Z. Jin, H. Enshaei, and J. M. Guerrero, “Ac ship microgrids: Control and power management optimization," Energies, vol. 11, no. 6, pp. 1-20, 2018, doi: 10.3390/en11061458.

[87] W. Liu et al., "Power quality assessment in shipboard microgrids under unbalanced and harmonic AC bus voltage," IEEE Trans. Ind. Appl., vol. 55, no. 1, pp. 765-775, 2019, doi: 10.1109/TIA.2018.2867330.

[88] M. D. Feste, M. Chiandone, D. Bosich, and G. Sulligoi, “Evolution of the Trieste Port: A real-time system for a coordinated cold ironing," Proc. - 2019 IEEE Int. Conf. Environ. Electr. Eng. 2019 IEEE Ind. Commer. Power Syst. Eur. EEEIC/I CPS Eur. 2019, 2019, doi: 10.1109/EEEIC.2019.8783436.

[89] B. Z. Jin, G. Sulligoi, R. Cuzner, L. Meng, J. C. Vasquez, and J. M. Guerrero, “Next-Generation Shipboard DC Power System,” IEEE Electrif. Mag., vol. 4, pp. 45-57, 2016.

[90] F. D’Agostino, D. Kaza, M. Martelli, G. P. Schiapparelli, F. Silvestro, and C. Soldano, “Development of a multiphysics realtime simulator for model-based design of a DC shipboard microgrid," Energies, vol. 13, no. 14, 2020, doi: 10.3390/en13143580.

[91] Z. Jin et al., "Specialized Hierarchical Control Strategy for DC Distribution based Shipboard Microgrids A combination of emerging DC shipboard power systems and microgrid technologies," pp. 10-12.

[92] K. Kwon and D. Park, “Load Frequency-Based Power Management for Shipboard DC Hybrid Power Systems,” pp. 142-147, 2020.

[93] S. German-Galkin and D. Tarnapowicz, "Energy optimization of the 'shore to ship' system - a universal power system for ships at berth in a port," Sensors (Switzerland), vol. 20, no. 14, pp. 1-21, 2020, doi: 10.3390/s20143815.

[94] G. F. Reed, B. M. Grainger, A. R. Sparacino, and Z. H. Mao, "Ship to grid: Medium-voltage dc concepts in theory and practice," IEEE Power Energy Mag., vol. 10, no. 6, pp. 70-79, 2012, doi: 10.1109/MPE.2012.2212613.

[95] G. For, "Guide for Direct Current (DC) Power Distribution Systems for Marine and Offshore Applications DIRECT CURRENT (DC) POWER DISTRIBUTION SYSTEMS FOR MARINE AND OFFSHORE APPLICATIONS," no. Dc, 2018, [Online]. Available: www.eagle.org.

[96] X. Zhaoxia et al., "Coordinated Control of a Hybrid-Electric-Ferry Shipboard Microgrid," vol. 5, no. 3, pp. 828-839, 2019.

[97] M. U. Mutarraf, Y. Terriche, K. A. K. Niazi, F. Khan, J. C. Vasquez, and J. M. Guerrero, "Control of hybrid diesel/PV/battery/ultra-capacitor systems for future shipboard microgrids," Energies, vol. 12, no. 18, pp. 1-23, 2019, doi: 10.3390/en12183460.

[98] N. B. Ahamad, M. Othman, J. C. Vasquez, J. M. Guerrero, and C. L. Su, “Optimal sizing and performance evaluation of a renewable energy based microgrid in future seaports," Proc. IEEE Int. Conf. Ind. Technol., vol. 2018-Febru, no. February, pp. 1043-1048, 2018, doi: 10.1109/ICIT.2018.8352322.

[99] S. G. Gennitsaris and F. D. Kanellos, "Emission-Aware and Cost-Effective Distributed Demand Response System for Extensively Electrified Large Ports," IEEE Trans. Power Syst., vol. 34, no. 6, pp. 4341-4351, 2019, doi: 10.1109/TPWRS.2019.2919949.

[100] Hamburg Port Authority, “Hamburg is staying on Course - The Port Development Plan to 2025," pp. 1-98, 2012.

[101] Ç. Iris and J. S. L. Lam, "A review of energy efficiency in ports: Operational strategies, technologies and energy management systems," Renew. Sustain. Energy Rev., vol. 112, no. April 2018, pp. 170-182, 2019, doi: 10.1016/j.rser.2019.04.069.

[102] M. H. Elwany, I. Ali, and Y. Abouelseoud, "A heuristics-based solution to the continuous berth allocation and crane assignment problem," Alexandria Eng. J., vol. 52, no. 4, pp. 671-677, 2013, doi: 10.1016/j.aej.2013.09.001.

[103] A. Liu, H. Liu, S. B. Tsai, H. Lu, X. Zhang, and J. Wang, “Using a hybrid model on joint scheduling of berths and quay cranesfrom a sustainable perspective," Sustain., vol. 10, no. 6, 2018, doi: 10.3390/su10061959. 
[104] Y. Wang, W. Ding, L. Dai, H. Hu, and D. Jing, "How would government subsidize the port on shore side electricity usage improvement?," J. Clean. Prod., vol. 278, p. 123893, 2021, doi: 10.1016/j.jclepro.2020.123893.

[105] S. G. Jayasinghe, L. Meegahapola, N. Fernando, Z. Jin, and J. M. Guerrero, “Review of ship microgrids: System architectures, storage technologies and power quality aspects," Inventions, vol. 2, no. 1, pp. 1-19, 2017, doi: 10.3390/inventions2010004.

[106] P. Xie et al., “Optimization-Based Power and Energy Management System in Shipboard Microgrid: A Review," IEEE Syst. J., pp. 1-13, 2021, doi: 10.1109/JSYST.2020.3047673.

[107] Y. Huang, H. Wang, A. Khajepour, H. He, and J. Ji, “Model predictive control power management strategies for HEVs : A review," J. Power Sources, vol. 341, pp. 91-106, 2017, doi: 10.1016/j.jpowsour.2016.11.106.

[108] Z. Sun and L. Li, "Potential capability estimation for real time electricity demand response of sustainable manufacturing systems using Markov Decision Process," J. Clean. Prod., vol. 65, pp. 184-193, 2014, doi: 10.1016/j.jclepro.2013.08.033.

[109] G. Subramani, V. K. Ramachandaramurthy, S. Padmanaban, L. Mihet-Popa, F. Blaabjerg, and J. M. Guerrero, “Grid-tied photovoltaic and battery storage systems with Malaysian electricity tariff - A review on maximum demand shaving," Energies, vol. 10, no. 11, 2017, doi: 10.3390/en10111884.

[110] A. Hirsch, Y. Parag, and J. Guerrero, "Microgrids: A review of technologies, key drivers, and outstanding issues," Renew. Sustain. Energy Rev., vol. 90, no. April, pp. 402-411, 2018, doi: 10.1016/j.rser.2018.03.040.

[111] P. H. Divshali and B. J. Choi, “Electrical market management considering power system constraints in smart distribution grids," Energies, vol. 9, no. 6, pp. 1-30, 2016, doi: 10.3390/en9060405.

[112] Y. Huang, H. Lan, Y. Y. Hong, S. Wen, and S. Fang, “Joint voyage scheduling and economic dispatch for all-electric ships with virtual energy storage systems," Energy, vol. 190, p. 116268, 2020, doi: 10.1016/j.energy.2019.116268.

[113] M. Othman, A. Anvari-Moghaddam, N. Ahamad, S. Chun-Lien, and J. M. Guerrero, "Scheduling of Power Generation in Hybrid Shipboard Microgrids with Energy Storage Systems," Proc. - 2018 IEEE Int. Conf. Environ. Electr. Eng. 2018 IEEE Ind. Commer. Power Syst. Eur. EEEIC/I CPS Eur. 2018, 2018, doi: 10.1109/EEEIC.2018.8494363.

[114] K. S. Rao, P. J. Chauhan, S. K. Panda, G. Wilson, X. Liu, and A. K. Gupta, “Optimal scheduling of diesel generators in offshore support vessels to minimize fuel consumption," IECON 2015 - 41st Annu. Conf. IEEE Ind. Electron. Soc., pp. 4726-4731, 2015, doi: 10.1109/IECON.2015.7392838.

[115] S. Pande and P. J. G. Ghodekar, "Computation of Technical Power Loss of Feeders and Transformers in Distribution System using Load Factor and Load Loss Factor," pp. 22-25, 2012.

[116] “Energy storage system for peak shaving International Journal of Energy Sector Management Article information :," no. April, 2016, doi: 10.1108/IJESM-01-2015-0003.

[117] C. Study, "Performance Assessment and Economic Analysis of a Gas-Fueled Islanded Microgrid - A Malaysian," 2019, doi: 10.3390/infrastructures4040061.

[118] F. C. Robert, “THE CRITICAL ROLE OF ANCHOR CUSTOMERS IN RURAL,” pp. 398-403, 2017.

[119] A. Davydova, R. Chakirov, Y. Vagapov, T. Komenda, and S. Lupin, “Coordinated In-home Charging of Plug-in Electric Vehicles from a Household Smart Microgrid."

[120] X. Ma, H. Qu, W. Pei, and H. Xiao, “Optimal Interactive Operation of Microgrid under Demand Response Based on Rolling Optimization Algorithm," Energy Procedia, vol. 145, pp. 97-102, 2018, doi: 10.1016/j.egypro.2018.04.016.

[121] A. H. Chowdhury, S. Alam, and A. Hossain, “Home Energy Management for Community Microgrids Using Optimal Power Sharing Algorithm," no. February, 2021.

[122] H. Geerlings, R. Heij, and R. Van Duin, “Opportunities for peak shaving the energy demand of ship-to-shore quay cranes at container terminals," 2018.

[123] R. Heij, “Opportunities for peak shaving electricity consumption at container terminals Opportunities for peak shaving electricity consumption at container terminals," no. February, 2015.

[124] G. Gross and F. D. Galiana, “Short-Term Load Forecasting,” vol. X, pp. 1558-1573, 1987. 
[125] I. A. Samuel, A. Emmanuel, I. A. Odigwe, and F. C. Felly-Njoku, “A Comparative Study of Regression Analysis and Artificial Neural Network Methods for Medium-Term Load Forecasting,” Indian J. Sci. Technol., vol. 10, no. 10, pp. 1-7, 2017, doi: 10.17485/ijst/2017/v10i10/86243.

[126] P. Bunnoon, K. Chalermyanont, and C. Limsakul, “A Computing Model of Artificial Intelligent Approaches to Mid-term Load Forecasting: a state-of-the-art- survey for the researcher," Int. J. Eng. Technol., vol. 2, no. 1, pp. 94-100, 2010, doi: 10.7763/ijet.2010.v2.106.

[127] W. Hong, M. Li, and G. Fan, Short-Term Load Forecasting by Artificial Intelligent Technologies. 2019.

[128] A. M. A.-K. Soliman Abdel-hady Soliman, “8 - Dynamic Electric Load Forecasting,” Electr. Load Forecast., no. ISBN 978012381543, pp. 291-352, 2010, doi: https://doi.org/10.1016/B978-0-12-381543-9.00008-7.

[129] F. Alasali, S. Haben, V. Becerra, and W. Holderbaum, “Optimal energy management and MPC strategies for electrified RTG cranes with energy storage systems," Energies, vol. 10, no. 10, 2017, doi: 10.3390/en10101598.

[130] F. Alasali, S. Haben, V. Becerra, and W. Holderbaum, “Day-ahead industrial load forecasting for electric RTG cranes,” J. Mod. Power Syst. Clean Energy, vol. 6, no. 2, pp. 223-234, 2018, doi: 10.1007/s40565-018-0394-4.

[131] M. Mehrzadi et al., "A deep learning method for short-term dynamic positioning load forecasting in maritime microgrids," Appl. Sci., vol. 10, no. 14, pp. 1-21, 2020, doi: 10.3390/app10144889.

[132] M. U. Mutarraf, Y. Terriche, K. A. K. Niazi, J. C. Vasquez, and J. M. Guerrero, Energy storage systems for shipboard microgridsA review, vol. 11, no. 12. 2018.

[133] A. Nayak, S. Lee, and J. W. Sutherland, "Storage trade-offs and optimal load scheduling for cooperative consumers in a microgrid with different load types," IISE Trans., vol. 51, no. 4, pp. 397-405, 2019, doi: 10.1080/24725854.2018.1460517.

[134] P. Palensky and D. Dietrich, "Demand side management: Demand response, intelligent energy systems, and smart loads," IEEE Trans. Ind. Informatics, vol. 7, no. 3, pp. 381-388, 2011, doi: 10.1109/TII.2011.2158841.

[135] M. Vahedipour-Dahraie, H. R. Najafi, A. Anvari-Moghaddam, and J. M. Guerrero, “Study of the effect of time-based rate demand response programs on stochastic day-ahead energy and reserve scheduling in islanded residential microgrids," Applied Sciences (Switzerland), vol. 7, no. 4. 2017, doi: 10.3390/app7040378.

[136] E. Commission, "Reducing emissions from the shipping sector - European Commission," European Commission. pp. 1, 2016.

[137] J.F. Sanz, G. Matute, G. Fernández, M. A. Alonso, and M. Sanz, “Analysis of european policies and incentives for microgrids,” Renew. Energy Power Qual. J., vol. 1, no. 12, pp. 874-879, 2014, doi: 10.24084/repqj12.516.

[138] J. F. Hansen and F. Wendt, "History and State of the Art in Commercial Electric Ship Propulsion, Integrated Power Systems , and Future Trends," vol. 103, no. 12, 2015.

[139] M. Acciaro, H. Ghiara, and M. I. Cusano, "Energy management in seaports: A new role for port authorities," Energy Policy, vol. 71, pp. 4-12, 2014, doi: 10.1016/j.enpol.2014.04.013.

[140] S. Sahoo, Y. Yang, and F. Blaabjerg, "Resilient Synchronization Strategy for AC Microgrids Under Cyber Attacks," vol. 36, no. 1, pp. 73-77, 2021.

[141] M. Rana, L. Li, and S. W. Su, “Cyber Attack Protection and Control of Microgrids,” vol. 5, no. 2, pp. 602-609, 2018, doi: 10.1109/JAS.2017.7510655. 